\title{
Application and Sensitivity Studies of the Orographic Cloud Model MCCP Pluvius
}
E. G. Chapman
D. J. Luecken
C. D. Whiteman

July 1987

This research has been funded as part of the National Acid Precipitation Assessment Program by the U.S. Environmental Protection Agency under a Related Services Agreement with the U.S. Department of Energy Contract DE-AC06-76RLO 1830 Interagency Agreement EPA-DW89930059

Pacific Northwest Laboratory Operated for the U.S. Department of Energy by Battelle Memorial Institute 
Although the research described in this article has been funded wholly or in part by the United States Environmental Protection Agency (EPA), it has not been subjected to EPA review and therefore does not necessarily reflect the views of EPA and no official endorsement should be inferred.

\title{
DISCLAIMER
}

This report was prepared as an account of work sponsored by an agency of the United States Government. Neither the United States Government nor any agency thereof, nor Battelle Memorial Institute, nor any of their employees, makes any warranty, expressed or implied, or assumes any legal liability or responsibility for the accuracy, completeness, or usefulness of any information, apparatus, product, or process disclosed, or represents that its use would not infringe privately owned rights. Reference herein to any specific commercial product, process, or service by trade name, trademark, manufacturer, or otherwise, does not necessarily constitute or imply its endorsement, recommendation, or favoring by the United States Government of any agency thereof, or Battelle Memorial Institute. The views and opinions of authors expressed herein do not necessarly state or reflect those of the United States Government or any agency thereof, or Battelle Memorial Institute.

\author{
PACIFIC NORTHWEST LABORATORY \\ operated by \\ BATTELLE MEMORIAL INSTITUTE \\ for the \\ UNITED STATES DEPARTMENT OF ENERGY \\ under Contract DE-AC06-76RLO 1830
}

\begin{tabular}{|c|c|}
\hline \multicolumn{2}{|c|}{ Printed in the United States of America } \\
\hline \multicolumn{2}{|c|}{$\begin{array}{c}\text { Availabie from } \\
\text { National Technical Information Service }\end{array}$} \\
\hline \multirow{4}{*}{\multicolumn{2}{|c|}{$\begin{array}{c}\text { National Technical Information Service } \\
\text { United States Department of Commerce } \\
5285 \text { Port Royal Road } \\
\text { Springfield, Virginia } 22161\end{array}$}} \\
\hline & \\
\hline & \\
\hline & \\
\hline \multirow{2}{*}{\multicolumn{2}{|c|}{$\begin{array}{l}\text { NTIS Price Codes } \\
\text { Microfiche A01 }\end{array}$}} \\
\hline & \\
\hline \multicolumn{2}{|c|}{ Printed Copy } \\
\hline & Price \\
\hline Pages & Codes \\
\hline $001-025$ & $\mathrm{~A} 02$ \\
\hline $026-050$ & $\mathrm{~A} 03$ \\
\hline $051-075$ & A04 \\
\hline $076-100$ & A05 \\
\hline $101-125$ & $A 06$ \\
\hline $126-150$ & $\mathrm{~A} 07$ \\
\hline $151-175$ & A08 \\
\hline $176-200$ & A09 \\
\hline $201-225$ & A010 \\
\hline $226-250$ & A011 \\
\hline $251-275$ & $\mathrm{~A} 012$ \\
\hline $276-300$ & $\mathrm{~A} 013$ \\
\hline
\end{tabular}


PNL -6292

APPLICATION AND SENSITIVITY STUDIES OF THE OROGRAPHIC CLOUD MODEL MCCP PLUVIUS
E. G. Chapman
D. J. Luecken
C. D. Whiteman

July 1987

This research has been funded as part of the National Acid Precipitation Assessment Program by the U.S. Environmental Protection Agency under a Related Services Agreement with the U.S. Department of Energy Contract DE-ACO6-76RLO 1830

Interagency Agreement EPA-DW89930059

Pacific Northwest Laboratory

Richland, Washington 99352 


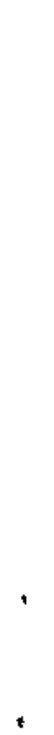

$+$ 


\section{SUMMARY}

The U.S. Environmental Protection Agency (EPA) has initiated a research program to investigate the causes of damage to forest ecosystems on mountains in the eastern United States. One mechanism that may explain the damage, which has been observed primarily on mountaintops, is the deposition of acidic cloud droplets on forest vegetation during frequent episodes when orographic clouds form over the mountains. The purpose of the present study, conducted for the EPA's Mountain Cloud Chemistry Program (MCCP), is to investigate the important processes leading to chemical transformations and pollutant deposition in shatlow orographic clouds using a numerical model.

In the investigation reported here, a special MCCP version of the PLUVIUS MOD 5.0 reactive storm model (MCCP PLUVIUS) was applied to conditions representative of Mt. Mitche11, North Carolina. Tests were also conducted to determine the sensitivity of the model to various meteorological and chemical parameters.

Results of the modeling investigation indicate that aqueous concentrations and deposition fluxes of pollutants are location dependent. The greatest concentrations occur at the edges of the cloud, where the liquid water content is low, and the greatest deposition flux occurs on the windward side of the mountain. For conditions considered representative of summertime conditions at Mt. Mitche11, predicted ion concentrations in deposited cloud water at a point corresponding to the MCCP field station are within the ranges actually observed. Sensitivity studies indicate that in-cloud oxidation of $\mathrm{SO}_{2}$ makes a limited contribution to total suTfate deposition for typical concentrations of $\mathrm{SO}_{2}, \mathrm{O}_{3}$, and $\mathrm{H}_{2} \mathrm{O}_{2}$. However, sulfate deposition predicted by MCCP PLUVIUS is extremely sensitive to the value selected for aerosol sulfate existing in the modeled air mass prior to cloud formation. Hydrogen ion deposition predicted by the model is strongly influenced by input values for gas-phase nitric acid and ammonia. Results of the modeling investigation are extended to Mt. Mitchell to gain improved understanding of the physicochemical mechanisms causing acidic deposition during orographic cloud events and to assist in an evaluation of the Mt. Mitchell MCCP field measurement program. 
-

,

' 


\section{ACKNOWLEDGMENTS}

This report is based on work funded as part of the National Acid Precipitation Assessment Program by the U.S. Environmental Protection Agency under a Related Services Agreement with the U.S. Department of Energy Contract DE-AC06-76RLO 1830, Interagency Agreement EPA-DW89930059. Dr. Ron Bradow of EPA is the Project Officer. Dick Easter is thanked for his thorough review of the manuscript and for helpful suggestions during the course of the work. Lorrie Roberts is thanked for her careful typing of the manuscript. 

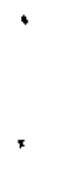


\section{CONTENTS}

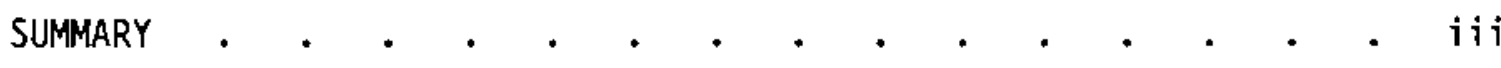

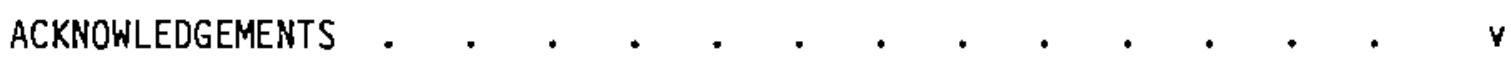

1.0 INTRODUCTION • . . . . . . . . . . . . . . . . . . . 1

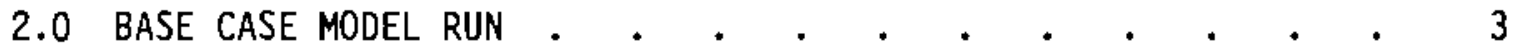

2.1 SELECTION OF VALUES FOR MODEL INITIALIZATION $• . \quad \cdot \quad \cdot \quad 4$

2.1.1 Meteorological Values . . . . . . . 4

2.1 .2 Chemical Values . . . . . . . . . . 5

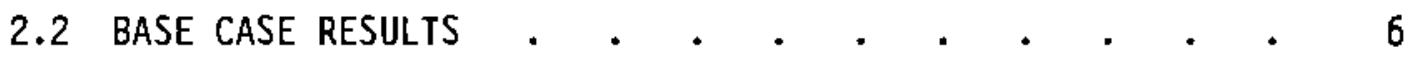

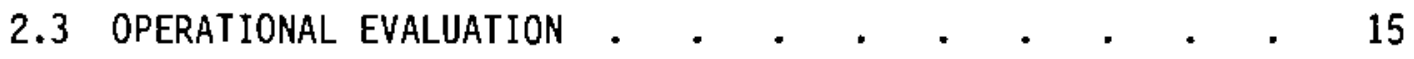

2.3.1 Initialization Test . . . . . . . . 15

2.3.2 Solubility Comparison . . . . . . . 18

2.3.3 Mass Balance Check . . . . . . . . . 18

2.4 IMPLICATIONS OF BASE CASE RESULTS . . . . . . . 23

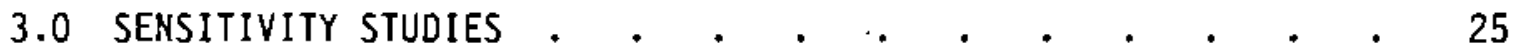

3.1 VARIATION OF METEOROLOGICAL PARAMETERS • • • • • • 26

3.1 .1 Deposition Velocity . . . . . . . . 26

3.1.2 Turbulent Eddy Diffusivity . • . . • . 28

3.1.3 Wind Speed . . . . . . . . . . 30

3.1 .4 Wind Shear . . . . . . . . . . 33

3.2 VARIATION OF CHEMICAL PARAMETERS . . . . . . . . 33

$3.2 .1 \mathrm{H}_{2} \mathrm{O}_{2} / \mathrm{SO}_{2}$ Ratios . . . . . . . . . . 33

3.2.2 Pre-Existing Sulfate Aerosol . . . . . . 37

3.2.3 Effect of Gas-Phase Ammonia and Nitric Acid . . 40

3.2.4 Gas/Aerosol Partitioning of Nitrogen Compounds . 43

4.0 DISCUSSION AND IMPLICATIONS OF CURRENT MODELING

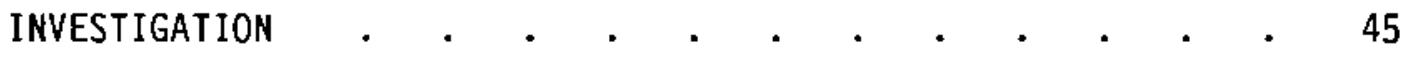

5.0 REFERENCES . . . . . . . . . . . . . . . . 51 


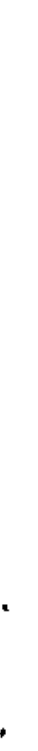

.

. 


\section{FIGURES}

1 Cloud Water Deposition Rate and Height of the Dividing Streamline Surface for the Base Case . . . . . . . 8

$2 \mathrm{SO}_{4}{ }^{2-}, \mathrm{NO}_{3}^{-}, \mathrm{H}^{+}$, and $\mathrm{NH}_{4}^{+}$Concentrations Within Depositing Cloud water for the Base Case. . . . . . . . . 11

3 Vertical Variation of $\mathrm{SO}_{4} 2-$ Within Cloud Water for the Base Case . . . . . . . . . . . . . . . 12

4 Deposition Fluxes for $\mathrm{SO}_{4}^{2-}, \mathrm{NO}_{3}^{-}, \mathrm{H}^{+}$, and $\mathrm{NH}_{4}^{+}$for the Base Case . . . . . . . . . . . . . . . 13

5 Schematic Representation of the Lifting of an Air Parcel . . 18

6 Grid Cell Spacing Within an MCCP PLUVIUS Air Column . . . 20

7 Cloud Water Deposition Rate for Various Values of $v_{d} \cdot$. . 27

$8 \mathrm{SO}_{4} 2$ - Concentrations Within Depositing Cloud Water for

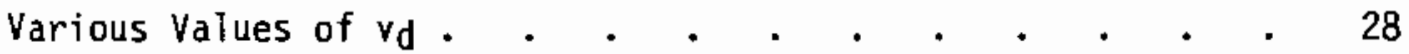

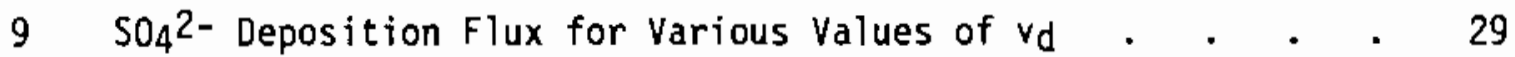

10 Cloud Water Deposition Rate at a Wind Speed of $10 \mathrm{~m} \mathrm{~s}^{-1}$. . 32

$11 \mathrm{SO}_{4}^{2-}, \mathrm{NO}_{3}-, \mathrm{H}^{+}$, and $\mathrm{NH}_{4}{ }^{+}$Concentrations Within Depositing Cloud Water for a wind Speed of $10 \mathrm{~m} \mathrm{~s}^{-1}$. . . . . . 32

12 Deposition Fluxes for $\mathrm{SO}_{4}^{2-}, \mathrm{NO}_{3}^{-}, \mathrm{H}^{+}$, and $\mathrm{NH}_{4}^{+}$for a Wind

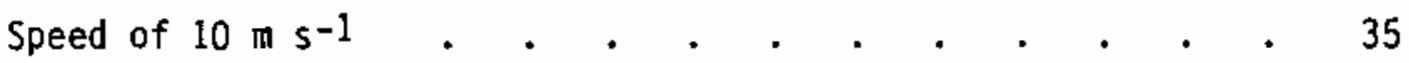

13 Percent $\mathrm{SO}_{2}$ Oxidized for Various $\mathrm{H}_{2} \mathrm{O}_{2} / \mathrm{SO}_{2}$ Ratios . . . . 36

14 Cumulative $\mathrm{SO}_{4}{ }^{2-}$ and $\mathrm{H}^{+}$Deposition for Various $\mathrm{H}_{2} \mathrm{O}_{2} / \mathrm{SO}_{2}$ Ratios . • . . . • . • • • . . • . 37

15 Cumulative $\mathrm{SO}_{4}{ }^{2-}$ and $\mathrm{H}^{+}$Deposition as a Function of the Initial Sulfate Aerosol Mixing Ratio (Fully Neutralized Aerosol) . . . . . . . . . . . . . . 39

16 Cumulative $\mathrm{SO}_{4}{ }^{2-}$ and $\mathrm{H}^{+}$Deposition as a Function of the Initial Aerosol Neutralization Ratio . . . . . . . . 39

17 Cumulative Deposition of $\mathrm{SO}_{4}{ }^{2-}, \mathrm{H}^{+}, \mathrm{NH}_{4}^{+}$, and $\mathrm{S}(+4)$ as a Function of the Initial $\mathrm{NH}_{3}$ Mixing Ratio . . . . . . 41

18 Cumulative Deposition of $\mathrm{SO}_{4}{ }^{2-}, \mathrm{H}^{+}, \mathrm{NO}_{3}{ }^{-}$, and $\mathrm{S}(+4)$ as a Function of the Initial $\mathrm{HNO}_{3}$ Mixing Ratio . . . . . 41 
19 Percent $\mathrm{SO}_{2}$ Oxidized as a Function of $\mathrm{NH}_{3}$ and $\mathrm{HNO}_{3}$ Mixing Ratios

as a Function of $\mathrm{NH}_{3}$ and $\mathrm{HNO}_{3} \mathrm{Mix}$ 


\section{TABLES}

1 Initial Clear-Air Mixing Ratios Selected as Input for the MCCP PLUVIUS Base Case . . . . . . . . . . 7

2 Translation Factors From the Height of the Dividing Streamline to the Height of Mt. Mitchell . . . . . . 10

3 Aqueous-Phase Pollutant Concentrations near the Mountain Top Predicted by MCCP PLUVIUS . • • • . • . . . 15

4 MCCP PLUVIUS Clear Air Output at Time $=540 \mathrm{~s}$ for (a) Base Case Inputs and (b) Base Case Inputs $\times 10$. . . . . 16

5 Mass Conservation Within MCCP PLUVIUS for Base Case Inputs and Three Deposition Velocities $\left(v_{d}\right)$. . . . . . . . . 22

6 In-Cloud $\mathrm{SO}_{2}$ Oxidation for the Base Case . . . . . . 23

7 Effect of Deposition Velocity on Cumulative Deposition . . 27

8 Effect of the Turbulent Eddy Diffusivity Constant on Cumulative Deposition . . . . . . . . . . . . . 30

9 Sumary of Input Conditions for Chemical Parameter Sensitivity Studies . . . . . . . . . . . 34 



\subsection{INTRODUCTION}

The U.S. Environmental Protection Agency (EPA) has initiated a research program to investigate the causes of forest ecosystem damage on mountains in the eastern United States. One mechanism that may explain the damage, which has been observed primarily on mountaintops, is the deposition of acidic cloud droplets on forest vegetation by orographic clouds. Such clouds occur frequently in events lasting several hours on mountains in eastern North America. A model called MCCP PLUVIUS has recentiy been developed by Luecken et al. (1987) to simulate such cloud events numerically. The purpose of the present study, conducted for EPA's Mountain Cloud Chemistry Program (MCCP), is to conduct initial tests of the sensitivity of MCCP PLUVIUS to different values of model input parameters.

MCCP PLUVIUS is a customized version of the PLUVIUS MOO 5.0 onedimensional reactive storm model developed and described by Easter and Hales (1984). MCCP PLUVIUS includes the relevant parameterizations to simulate in-cloud processes leading to chemical transformations and cloud water deposition in shallow, nonprecipitating orographic clouds. The model includes aerosol scavenging, nonreactive gas scavenging, aqueous-phase $\mathrm{SO}_{2}$ reactions, and cloud water deposition. Thirty chemical and water species in various phases are carried as dependent variables in MCCP PLUVIUS simulations.

The purpose of the present report is to relay the results of a modeling investigation conducted using MCCP PLUVIUS for the MCCP site at Mt. Mitche11, North Carolina. The investigation includes a base case scenario with chemical and meteorological inputs that are within the typical range of sumnertime values observed at Mt. Mitchell. Sensitivity studies were also conducted to identify model parameters that strongly influence aqueous $\mathrm{SO}_{2}$ oxidation rates and the deposition of sulfate and hydrogen ions to the mountain surface. In these sensitivity studies, emphasis was placed on determining the effect of various chemical constituents, rather than on meteorological parameters. Emphasis was also placed on examining the effect of chemical parameters where limited or no field measurements existed for Mt. Mitchell. 
The sensitivity tests of MCCP PLUVIUS are expected to be useful in evaluating the relative importance of various scavenging and chemical pathways during orographic cloud events at Mt. Mitchell so that effective MCCP meteorological and chemical measurement strategies can be developed or refined. The model will also assist in evaluating the utility of the MCCP data base in future investigations of processes leading to observed chemical and cloud characteristics.

We begin with a detailed description of the base case model run, followed by a review of the major results of the sensitivity studies. Implications of the modeling results relative to the "real-world" situation at Mt. Mitchell are discussed and suggestions are made for enhancing both the measurement and modeling components of the MCCP. 


\subsection{BASE CASE MODEL RUN}

Orographic or cap clouds can appear to remain stationary over a mountain sumnit for many hours. These clouds are actually formed dynamically. The cloud is maintained by an uninterrupted flow of air over the mountain, with condensation taking place on the windward side of the mountain and evaporation taking place on the leeward side. This flow can be visualized as a succession of vertical columns of air that are carried over the mountain. The modeling approach in MCCP PLUVIUS is to perform calculations in a Lagrangian (or columnfollowing) sense for a single column of air as it crosses the mountain barrier at Mt. Mitchell, North Carolina. Cloud formation, chemical transformation, and cloud-water deposition processes take place within the moving column. If conditions in the approaching airstream are assumed to remain constant in time (i.e., steady-state), physical processes modeled in the single column will be representative of processes occurring in all succeeding columns.

As the column of air containing gaseous and aerosol pollutants is lifted up the mountain, the moisture in the column condenses on available aerosols, which act as cloud-condensation nuclei, to form a cloud. Formation of the liquid water droplets triggers the establishment of gas/aqueous-phase equilibria of various pollutants and initiates aqueous-phase chemical reactions. Liquid water and chemical species dissolved in this water are delivered to the mountain surface as cloud droplets are deposited at the base of the column. This process continues, with further lifting increasing the cloud water concentrations until the air column reaches the mountain sumnit. Descent of the column on the lee side of the mountain results in warming and evaporation of the cloud droplets until, at a certain altitude, the cloud completely dissipates and the column again contains clear air with no liquid water.

This chapter describes in detail one base case study that simulates the processes described above. In this study, we attempt to model typical conditions for the Mt. Mitchell MCCP site to reasonably approximate actual processes and the spatial distribution patterns of chemical pollutants on the mountain. The base case, which is very loosely based on the Mt. Mitchell cloud event that occurred August 30-31, 1986, corresponds to the example 
application described in the MCCP PLUVIUS user's guide (Luecken et al. 1987). Rather than trying to exactly reproduce field measurements, we use this base case to illustrate general trends in the deposition process. The base case results aiso provide a means to evaluate the numerical operation of the model.

We begin this chapter with a discussion of our rationale for selecting certain values for required MCCP PLUVIUS inputs. Results of the base case run and operational evaluation are then described. The material presented should not be interpreted as an in-depth study of one particular cloud event, but merely as our attempt to assess model performance and gain understanding of the factors affecting pollutant deposition on Mt. Mitchell under relatively typical meteorological and aerometric conditions.

\subsection{SELECTION OF VALUES FOR MODEL INITIALIZATION}

\subsubsection{Meteorological values}

The model sensitivity tests were designed primarily to investigate chemical transformations in an orographic cloud and the resulting deposition of cloud water. For this purpose, it was desirable to use the model with a simple, but realistic, orographic cloud. Therefore, temperature and humidity profile data from the 0000 Greenwich Mean Time (GMT) rawinsonde sounding at Greensboro, North Carolina, on August 31, 1986, were used to initialize the model and to calculate the height of the critical dividing streamline. The reader is referred to the report by Luecken et al. (1987) for details on these calculations, a summary of which is given here. Calculations were made under the assumption that winds throughout the sounding depth were from 120 degrees true north at a speed of $7.5 \mathrm{~m} \mathrm{~s}^{-1}$. For winds from this direction, Mt. Mitchell's topographic cross section can be approximated mathematically by a cosine function, such that ground elevation above sea level in meters $\left(z_{m}\right)$ is given as

$$
z_{\pi}=1219+818 \cos ^{4}(\pi y / 10800)
$$

where $y$ is distance downwind from the mountain summit. 
The dividing streamline analysis results in the following formula for the dividing streamline height $\left(z_{d}\right)$ in meters as a function of $y$ :

$$
z_{d}(y)=h_{c}+\left(h-h_{c}\right) \exp \left[-0.5\left(y / \sigma_{y}\right)^{2}\right]
$$

In this equation, the mountain top height, $h$, was 2040 m (height of Mt. Mitche11), $\sigma_{y}$ was chosen to be one half the mountain width at the height of the lifting condensation level, and $h_{C}$, the height of the critical streamline, was calculated using the method outlined by Luecken et al. (1987). The lifting condensation level was $100 \mathrm{~m}$ above $h_{c}$, where the mountain width was $3000 \mathrm{~m}$. Thus $\sigma y$ was chosen to be $1500 \mathrm{~m}$.

The column upwind of the mountain was initialized with profiles of temperature and dew point temperature from the Greensboro rawinsonde sounding from the level of the critical dividing streamline $\left(h_{c}=1590 \mathrm{~m}\right)$ to the level of the top of the column $(2090 \mathrm{~m})$. The initial sounding in this height interval (Luecken et al. 1987, Figure 2) could be characterized as consisting of a shallow moist layer of air surmounted by a deeper dry layer. A cloud would begin to form in the column after an initial lifting of only $100 \mathrm{~m}$.

The assumptions concerning horizontal winds made in the dividing streamine calculations (winds from 120 degrees at $7.5 \mathrm{~m} \mathrm{~s}^{-1}$ ) were also made within the model. Additionally, it was assumed that wind velocity was independent of height and time. The cloud was formed as the horizontal wind transported the base of the vertical air column up the path of the dividing streamline.

\subsubsection{Chemical values}

As explained by Luecken et al. (1987), MCCP PLUVIUS requires initial, upwind mixing ratios of thirteen chemical species at the bottom of the modeled air column as part of its input data file. These mixing ratios are used to generate vertical pollutant profiles with which the model is initialized. Input values for some species were selected from ranges of concentrations experimentally observed at Mt. Mitchell. However, not all chemical species included in the model have actually been measured at the site. Initial concentrations for these compounds were selected from a survey of values in the 
literature, with locations of these alternate measurements as similar as possible to Mt. Mitchell. Table 1 lists the selected input values for chemical species included in MCCP PLUVIUS along with the approximate ranges from which each value was chosen.

\subsection{BASE CASE RESULTS}

As discussed by Luecken et al. (1987), MCCP PLUVIUS output can consist of both an ASCII file and a disk file. Both files list the vertical concentrations of each pollutant species in the air column along with vertical temperature and pressure profiles for each user-specified time step. The ASCII file output for selected time steps in the base case run have been tabulated by Luecken et al. (1987). Valuable insights can be gained not only from studying these concentration profiles but also from using the disk file in postprocessing operations to calculate deposition fluxes of pollutants to the mountain surface. The flux in micromoles per square meter per hour can be calculated as

$$
\text { Pollutant Deposition Flux }=3.6 \times 10^{10} v_{d} \tilde{C}_{k}
$$

where $3.6 \times 1010$ is a conversion factor from moles per square centimeter per second to micromoles per square meter per hour, $v_{d}$ is the deposition velocity in centimeters per second, and $\tilde{C}_{k}$ is the concentration of pollutant dissolved in cloud water at the bottom grid cell in moles per liter of water. The value of $\tilde{C}_{k}$ can be obtained from MCCP PLUVIUS disk and ASCII output files by

$$
\tilde{C}_{k}=C_{k} /\left(0.018 C_{w}\right)
$$

where $C_{k}$ is pollutant concentration in the bottom grid cell in the normal MCCP PLUVIUS units of moles per cubic centimeter of space, $C_{W}$ is the liquid water concentration in the bottom grid cell in moles of water per cubic centimeter of space, and 0.018 is a conversion factor from moles of water per cubic centimeter of space to liters of water per cubic centimeter of space. 
TABLE 1. Initial Clear-Air Mixing Ratios Selected as Input for the MCCP PLUVIUS Base Case

\begin{tabular}{|c|c|c|c|}
\hline Chemical Parameter & $\begin{array}{l}\text { Input Mixing } \\
\text { Ratio (ppb) } \\
\end{array}$ & $\begin{array}{l}\text { Approximate } \\
\text { Range (ppb) }\end{array}$ & Source \\
\hline $\mathrm{SO}_{2}$ & 2. & $1.5-2.0$ & (a) \\
\hline $\mathrm{SO}_{4}^{2-}$ & 2. & $1.0-7.0$ & (a) \\
\hline $\mathrm{NO}_{3}-$ & 1. & $0.1-3.0$ & (b) \\
\hline $\mathrm{HNO}_{3}$ & 3. & $1.0-9.0$ & (b) \\
\hline $\mathrm{NH}_{4}+$ & 5. & $1.4-16.0$ & (c) \\
\hline $\mathrm{NH}_{3}$ & 2. & $0.5-9.0$ & (a) \\
\hline $\mathrm{H}_{2} \mathrm{O}_{2}$ & 1. & $0 .-3.0$ & (d) \\
\hline $0_{3}$ & 70 . & $25-125$ & (a) \\
\hline $\mathrm{HCHO}$ & 2. & --- & (d) \\
\hline Cations $(+2)$ & 0.4 & -- & $(c, e)$ \\
\hline Cations $(+1)$ & 0.4 & -- & $(c, e)$ \\
\hline Anions $(-2)$ & 0.4 & --- & $(c, e)$ \\
\hline Anions $(-1)$ & 0.4 & --- & $(c, e)$ \\
\hline
\end{tabular}

(a) Typical values measured at Mt. Mitchell.

(b) Based on $\mathrm{NO}_{\mathrm{x}}$ measured at Mt. Mitchell and work of Kelly, Stedman, and Kok (1979) and Spicer (1982).

(c) Selected to simulate a fully neutralized aerosol.

(d) Influenced by Seigneur and Saxena's (1984) estimate for the Adirondacks and by the airborne measurements of Heikes et al. (1987).

(e) Influenced by observed concentrations of $\mathrm{Ca}^{2+}, \mathrm{Mg}^{2+}, \mathrm{Na}^{+}, \mathrm{K}^{+}, \mathrm{Cl}^{-}$, and $\mathrm{PO}_{4}{ }^{3-}$ in Mt. Mitchell cloud water. 
Similarly, the rate of cloud water deposition to the mountain surface (in effect, a precipitation rate) in millimeters per hour can be calculated from

$$
\text { Cloud-Water Deposition Rate }=6.48 \times 105 \mathrm{vd}_{\mathrm{d}} \mathrm{C}_{\mathrm{W}}
$$

where the numerical constant is a conversion factor from centimeters per second to millimeters per hour.

Figure 1 shows the rate of cloud water deposition as a function of time from the start of the simulation. Also plotted in this figure is the height of the base of the air column above the initial critical dividing streamline level $\left(z_{d}-h_{C}\right)$ as a function of time $(t)$. This latter curve defines the surface, relative to a datum level of $h_{c}$, along which the air column is lifted to form the orographic cloud.

In MCCP PLUVIUS, the independent variable is the transport time of the column. In this steady-state application of the model, the transformation

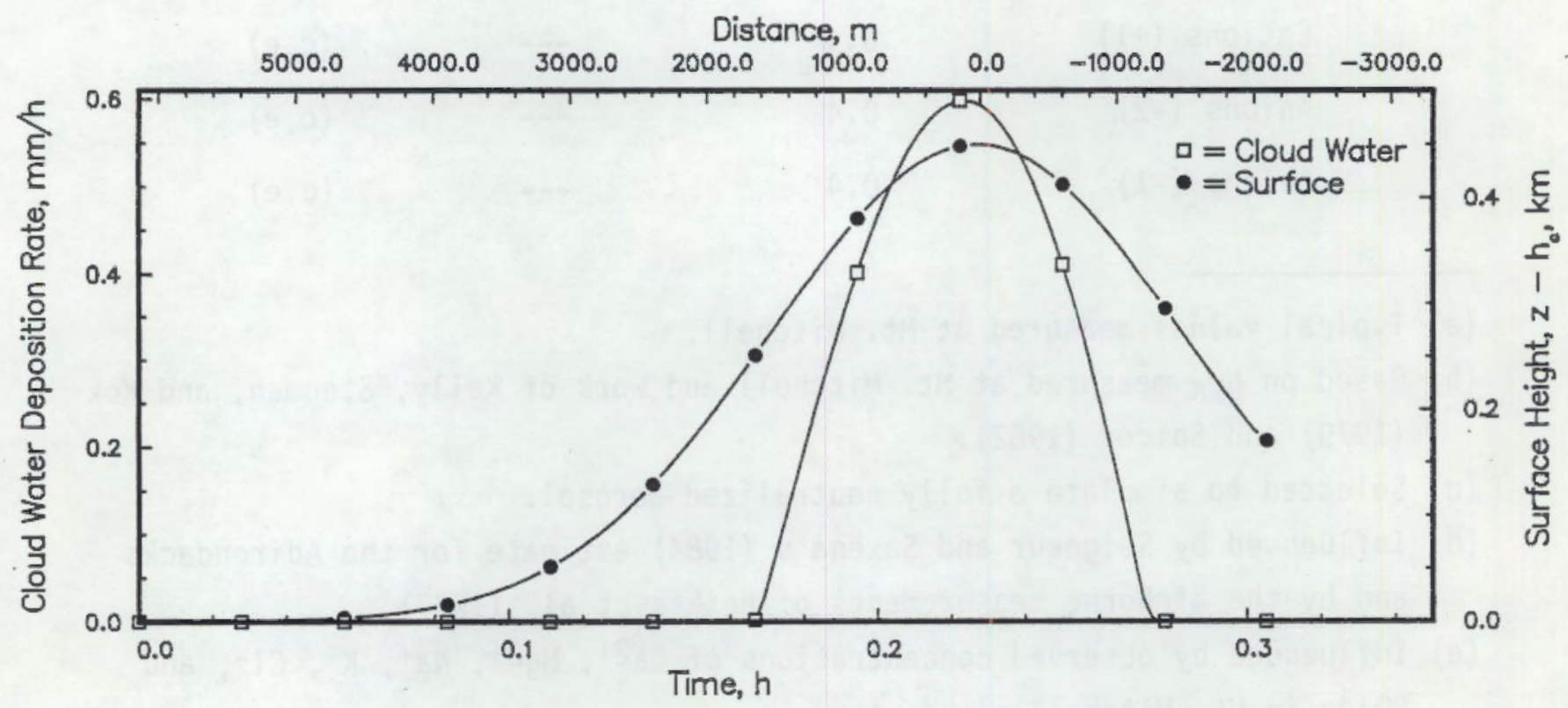

FIGURE 1. Cloud Water Deposition Rate and Height of the Dividing Streamline Surface for the Base Case (Note that the cloud water deposition rate curve should be used with the left-hand $y$ axis and the surface height curve with the right-hand $y$ axis.) 
from the time coordinate to the horizontal distance coordinate, $y$, can be given by the simple expression

$$
y=L-U_{a} t
$$

where $L$ is the upwind distance of the column at model initialization ( $L=$ $6150 \mathrm{~m}), U_{a}=7.5 \mathrm{~m} \mathrm{~s}^{-1}$, and $t$ is the time in seconds elapsed since model initialization. Thus, the time into the model simulation can be converted into a distance from the mountain top, as shown on the $x$ axes in Figure 1 .

For the model calculations, it is convenient to use the vertical distance above sea level, $\mathbf{z}$, as the height coordinate. Using this convention, the distance above the base of the column at model initialization can be given as $z-h_{c}$ and the distance above the base of the column at any given time is $z-z_{d}$, where $h_{c}$ and $z_{d}$ are as defined in Section 2.1.1. Coordinate system relationships and mountain and dividing streamline heights are illustrated for the model simulation in Table 2. Translation of results to the actual surface of Mt. Mitchell can be made using the factors given in this table. For example, at a model time of $0.20 \mathrm{~h}$, the air column is at a horizontal distance of $750 \mathrm{~m}$ from the mountain summit. The base of the air column is located at an altitude of $1987 \mathrm{~m}$, which is a vertical distance above the initial starting height $\left(h_{\mathrm{C}}\right)$ of $397 \mathrm{~m}$ (see Figure 1 ). This corresponds to an altitude of approximately $1963 \mathrm{~m}$ on the actual surface of Mt. Mitchell. Because MCCP field measurements are generally made high on the mountain top, where the height of the dividing streamline approaches the actual topographic height, the model user is advised to consider the calculated deposition at a given simulation time as representing surface deposition to the actual mountain at the corresponding position relative to the summit. Thus, the deposition calculated at a model time of $0.20 \mathrm{~h}$ should be considered representative of the deposition occurring at an altitude of $1963 \mathrm{~m}$ on the windward side of Mt. Mitchell.

The curves in Figure 1 clearly show the evolution of the cloud as the air column is lifted. The cloud starts forming approximately $0.16 \mathrm{~h}$ into the simulation. Cloud depth and cloud water deposition rate are both maximums at the mountain top, at a simulation time of approximately $0.23 \mathrm{~h}$. This situation 
TABLE 2. Translation Factors from the Height of the Dividing Streamline to the Height of Mt. Mitchell

\begin{tabular}{|c|c|c|c|}
\hline \multirow{2}{*}{$\begin{array}{r}\text { Time } \\
\text { (h) } \\
\end{array}$} & \multirow{2}{*}{$\begin{array}{c}\text { Distance from } \\
\text { Mountain Top } \\
\text { (m) } \\
\end{array}$} & \multicolumn{2}{|c|}{ Height (m) } \\
\hline & & Streamline & Mountain \\
\hline 0.175 & 1425 & 1877 & 1794 \\
\hline 0.183 & 1200 & 1917 & 1858 \\
\hline 0.192 & 975 & 1955 & 1915 \\
\hline 0.200 & 750 & 1987 & 1963 \\
\hline 0.208 & 525 & 2013 & 2000 \\
\hline 0.217 & 300 & 2031 & 2025 \\
\hline 0.225 & 75 & 2039 & 2036 \\
\hline 0.233 & -150 & 2038 & 2034 \\
\hline 0.242 & -375 & 2026 & 2018 \\
\hline 0.250 & -600 & 2006 & 1989 \\
\hline 0.258 & -825 & 1977 & 1948 \\
\hline 0.267 & -1050 & 1943 & 1896 \\
\hline
\end{tabular}

is expected, because at this point the moist air column has been lifted to its maximum height, where the maximum condensation occurs, yielding the highest concentration of liquid water. The cloud depth at the mountain summit is approximately $200 \mathrm{~m}$, with the cloud base approximately $350 \mathrm{~m}$ below the summit.

Figure 2 illustrates the concentrations of four major pollutants ( $\mathrm{SO}_{4}{ }^{2-}$, $\mathrm{NO}_{3}{ }^{-}, \mathrm{NH}_{4}{ }^{+}$, and $\mathrm{H}^{+}$) dissolved in the depositing cloud water. All four ions demonstrate the same pattern of highest concentrations at the windward and leeward edges of the cloud and lowest concentrations near the mountaintop. Those pollutants having the greatest initial clear-air mixing ratios yield the highest aqueous-phase concentrations. The concentrations at the beginning of the cloud event are large because the highest concentration of clear-air pollutants within the model domain are dissolving in the smallest amount of cloud water. Once in the aqueous phase, the pollutant concentrations begin to decrease because of dilution; more liquid water condenses as the air column continues its rise up the mountain. Dissolved pollutants are then depleted 


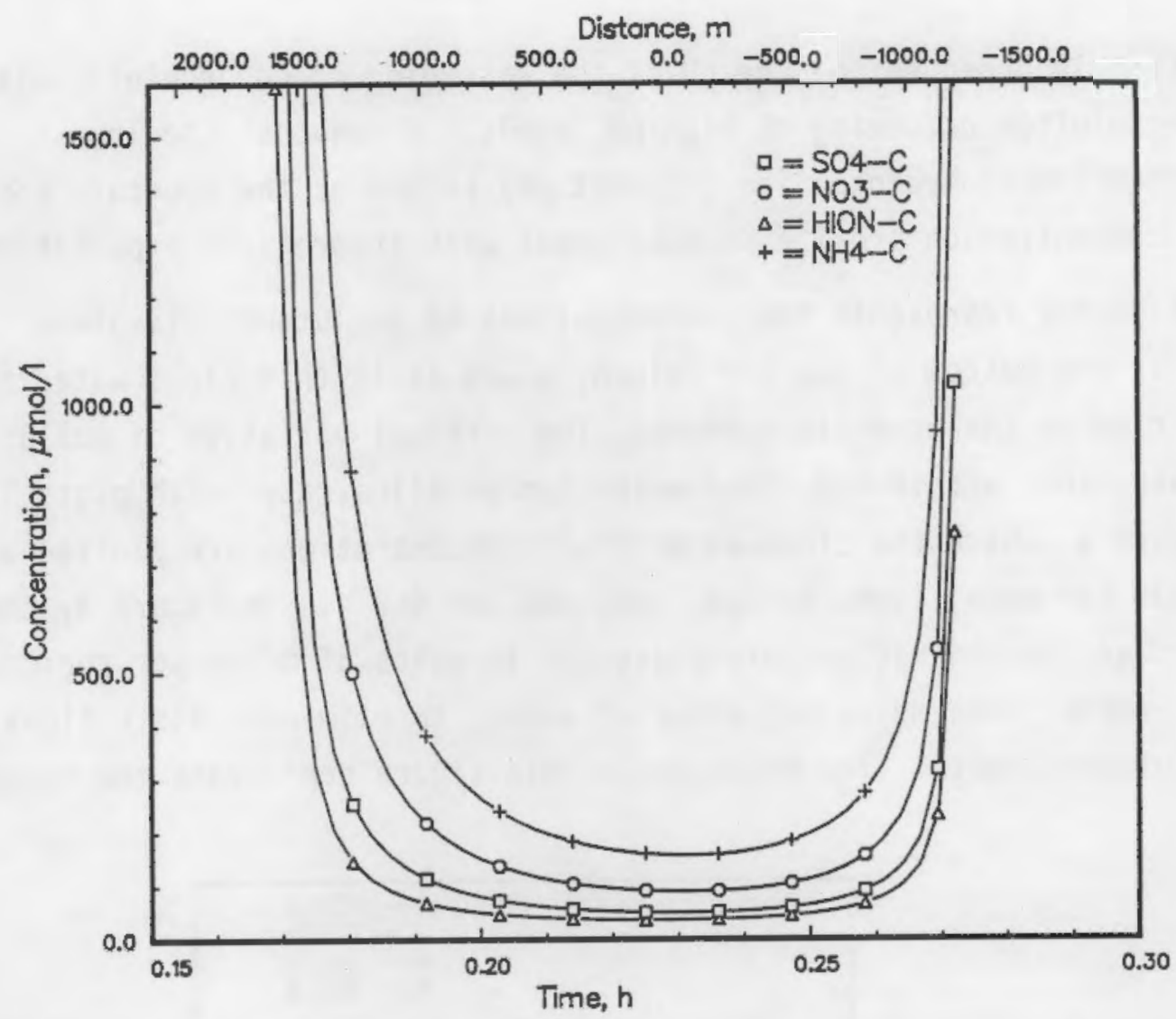

FIGURE 2. $\mathrm{SO}_{4}{ }^{2-}(\mathrm{SO} 4-\mathrm{C}), \mathrm{NO}_{3}-(\mathrm{NO} 3-\mathrm{C}), \mathrm{H}^{+}(\mathrm{HION}-\mathrm{C})$, and $\mathrm{NH}_{4}{ }^{+}\left(\mathrm{NH}_{4}-\mathrm{C}\right)$ Concentrations Within Depositing Cloud Water for the Base Case

by cloud-droplet deposition on the mountain surface, also contributing to the decrease in concentration. Once the air column reaches the crest and begins to descend down the lee side of the mountain, cloud water begins to evaporate. This process causes pollutant concentrations to increase until the cloud completely evaporates and pollutants are released to the clear air.

Pollutant concentration profiles in the depositing cloud water were similar to those in Figure 2 for all species except dissolved $\mathrm{SO}_{2}$ (S(IV)), concentrations of which were highest at the mountain top. The S(IV) concentrations, defined as

$$
[\mathrm{S}(\mathrm{IV})]=\left[\mathrm{SO}_{2}(\mathrm{aq})\right]+\left[\mathrm{HSO}_{3}-\right]+\left[\mathrm{SO}_{3}{ }^{2-}\right]
$$


are strongly dependent on the $\mathrm{pH}$ of the absorbing cloud droplets, with more $\mathrm{SO}_{2}$ dissolution occurring at high $\mathrm{pH}$ levels. Given that the lowest concentration of hydrogen ion (highest $\mathrm{pH}$ ) occurs at the mountain top, the S(IV) concentration profile is consistent with theoretical expectations.

Figure 2 represents the concentrations of pollutants dissolved in cloud water at the bottom of the air column, since it is this cloud water that is depositing on the mountain surface. The vertical variation of pollutant concentrations within the cloud water can be illustrated with plots like those in Figure 3 , where the cloud-water $\mathrm{SO}_{4} 2-$ concentrations are plotted against altitude for model times of $600,720,840$ and $960 \mathrm{~s}$. In Figure 3, the cloudborne $\mathrm{SO}_{4}{ }^{2-}$ concentrations are presented in units of moles per cubic meter of space, rather than moles per liter of water, to eliminate distortions caused by dilution effects. The ordinate in this figure represents the height above

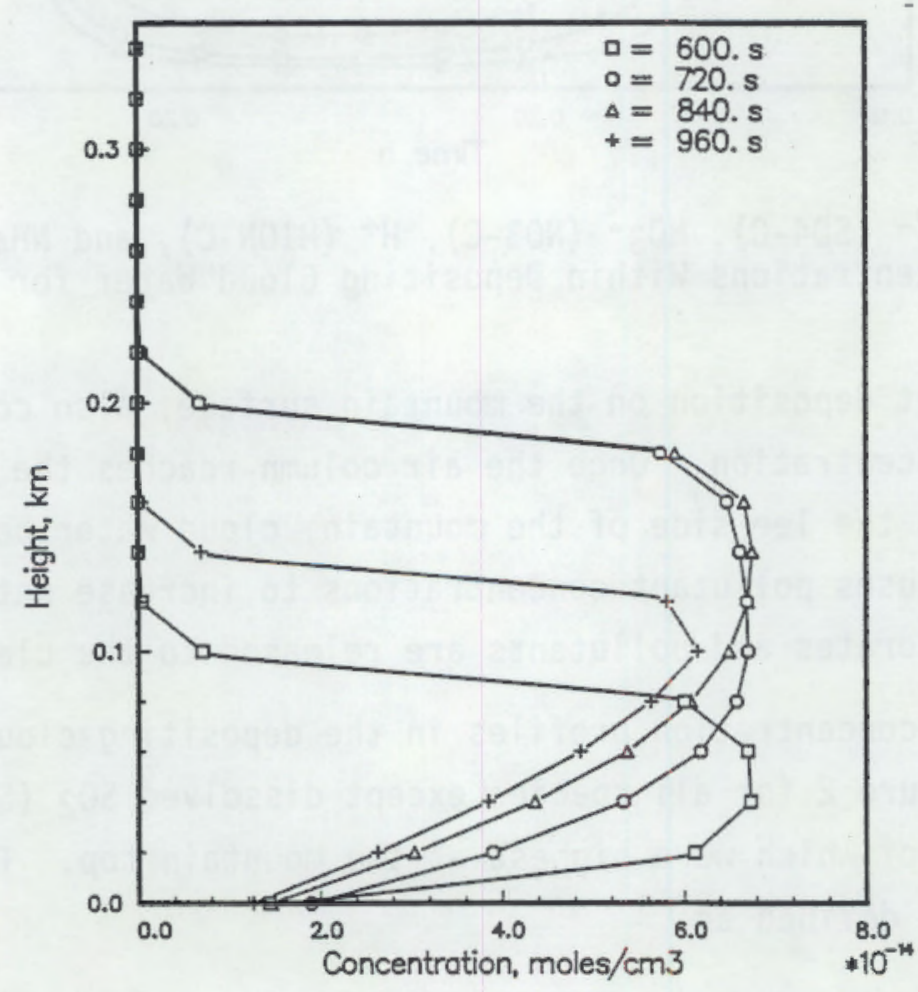

FIGURE 3. Vertical Variation of $\mathrm{SO}_{4}{ }^{2-}$ Within Cloud Water for the Base Case. (Concentration units are moles per cubic centimeter of space to eliminate dilution effects; concentrations are zero where no cloud exists.) 
the bottom of the air column, modeled using a grid with constant cell spacing that moves with the air column. The species profile shapes are a function of the cloud-water concentration fields, because the total depth of the cloud layer increases until the mountain top is reached (cloud depth of $200 \mathrm{~m}$ at $\mathrm{t}=840 \mathrm{~s}$ ) and decreases thereafter. Cloud water $\mathrm{SO}_{4}{ }^{2-}$ - concentrations above $0.11 \mathrm{~km}$ at $t=600 \mathrm{~s}$ equal zero, because no cloud has formed at this point. The depletion of $\mathrm{SO}_{4}{ }^{2-}$ concentrations due to cloud-droplet deposition to the mountain surface can be seen in the lower level of the cloud. This depletion affects $\mathrm{SO}_{4}{ }^{2-}$ concentrations up to levels of about $100 \mathrm{~m}$ above the cloud base. Other pollutant species show similar vertical profiles.

Figure 4 illustrates the deposition fluxes of $\mathrm{SO}_{4}^{2-}, \mathrm{NO}_{3}-, \mathrm{H}^{+}$, and $\mathrm{NH}_{4}^{+}$ to the mountain surface as a function of time. The instant that the cloud forms, the molar concentrations of cloud-borne species are nearly constant in height throughout the depth of the cloud. However, a shallow layer at the

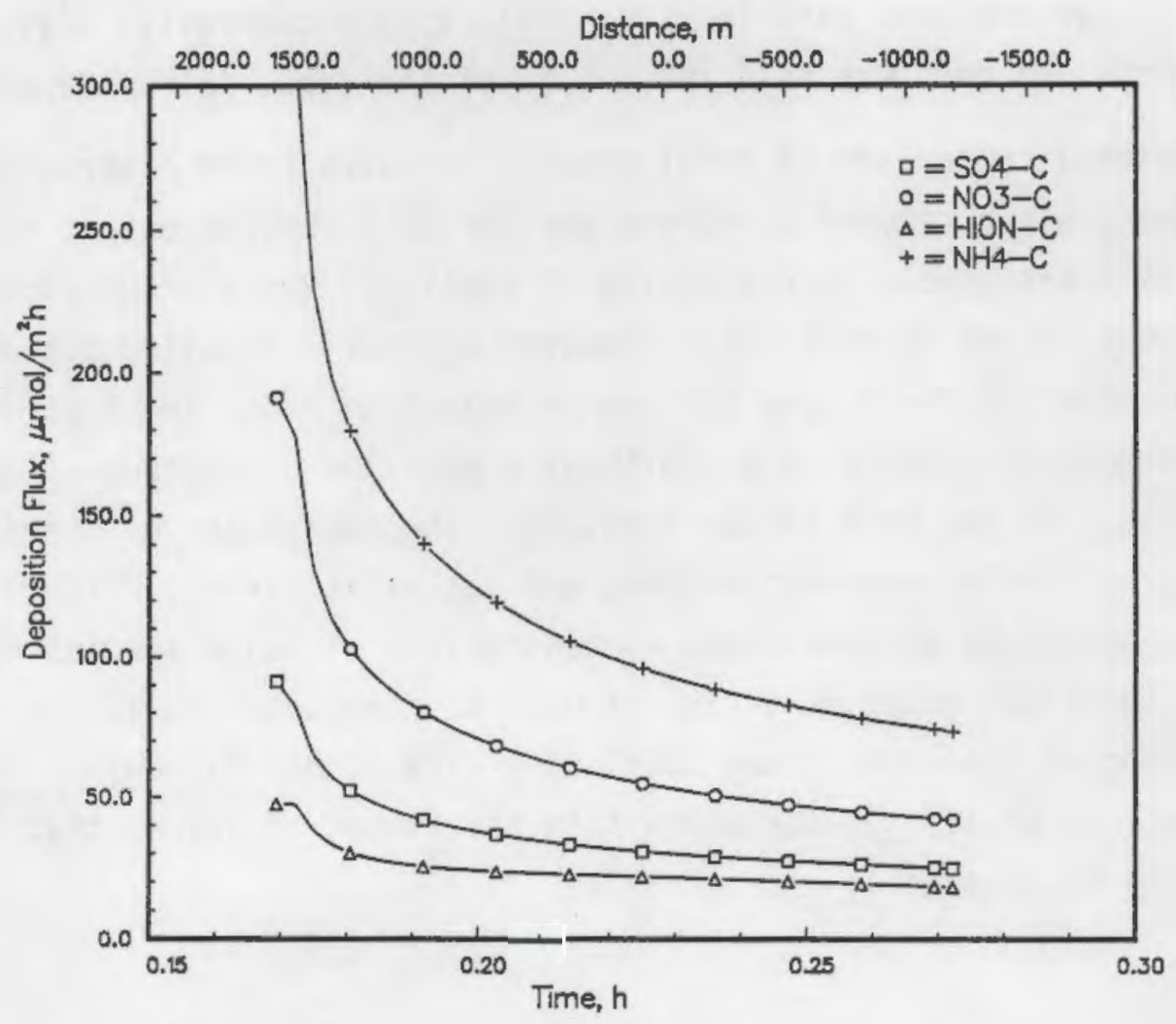

FIGURE 4. Deposition Fluxes for $\mathrm{SO}_{4}{ }^{2-}, \mathrm{NO}_{3}-, \mathrm{H}^{+}$, and $\mathrm{NH}_{4}{ }^{+}$for the Base Case 
surface is quickly depleted by deposition. This process produces the rapid, initial decline in deposition flux seen in Figure 4. This depletion continues with time so that species concentrations at the surface (in moles per cubic centimeter of space) and the deposition flux continue to decrease. Deposition fluxes are thus greatest on the windward side of the mountain at the fringe of the cloud.

Figure 4 also illustrates that slightly different deposition rates exist for the same altitude on both sides of the mountain. This situation is a result of depletion of the cloud by deposition and turbulent diffusion of water out of the moist cloud layer.

Deposition flux curves were similar to those in Figure 4 for all species except S(IV), whose greatest flux occurred at the mountain top. This result is a consequence of the highest S(IV) concentrations occurring at this location. However, S(IV) scavenging is a negligible contributor to the total sulfur deposition for the base case input conditions; the cumulative S(IV) deposition of $6 \times 10^{-12} \mathrm{~mol} \mathrm{~cm}-2$ was only about $1.6 \%$ of the total sulfur deposited.

A general comparison of model predictions with field observations at Mt. Mitchell was attempted to assess whether MCCP PLUVIUS output for this example is a reasonable approximation of reality. Model predictions and actual observations cannot be rigorously compared without a detailed set of chemical and meteorological field data for use in selecting model input parameters and for assessment of results, i.e., without a detailed case study of an actual cloud event. To the best of our knowledge, the needed set of chemical and meterological field observations does not yet exist for Mt. Mitchell. Table 3 lists the predicted aqueous-phase concentrations of major species dissolved in deposited cloud water at a time of $0.23 \mathrm{~h}$, corresponding approximately to the location of the mountaintop monitoring site at Mt. Mitchell. The modeled concentrations of all species are within the ranges of values that have been observed on Mt. Mitchell. 
TABLE 3. Aqueous-Phase Pollutant Concentrations near the Mountaintop Predicted by MCCP PLUVIUS. (Concentrations are micromoles per liter of water unless otherwise noted.)

\begin{tabular}{|c|c|}
\hline Species & Concentration \\
\hline $\mathrm{NO}_{3}-$ & 89 \\
\hline $\mathrm{SO}_{4}^{2-}$ & 50 \\
\hline $\mathrm{NH}_{4}^{+}$ & 155 \\
\hline $\mathrm{H}^{+}$ & 40 \\
\hline Liquid Water Content & $0.29 \mathrm{~g} \mathrm{~m}^{-3}$ \\
\hline
\end{tabular}

\subsection{OPERATIONAL EVALUATION}

Base case results were used to check fundamental code operation and assess whether or not the model was executing as planned. Three simple studies were performed: an initialization test, a solubility comparison, and a mass-balance check.

\subsubsection{Initialization Test}

The initialization test was used to confirm that information in the data input file was being read correctly and processed to provide proper model initialization. Base case output at time zero was compared to input values converted from the input data file units of parts per billion (ppb) to standard MCCP PLUVIUS units of moles per cubic centimeter of space. Initial values were then increased by a factor of ten and model output at selected time intervals before cloud formation were compared to the base case output. This comparison is made before cloud formation because, as discussed in Chapter 3 , individual pollutant concentrations influence aqueous-phase reaction rates, concentration profiles, and deposition totals. Table 4 lists the liquid water (CLOUD), sulfate aerosol $\left(\mathrm{SO}_{4}-\mathrm{A} 1\right)$, sulfur dioxide $\left(\mathrm{SO}_{2}-\mathrm{G}\right)$, nitrate aerosol $\left(\mathrm{NO}_{3}-\mathrm{Al}\right)$, ammonium aerosol $\left(\mathrm{NH}_{4}-\mathrm{Al}\right)$, ammonia gas $\left(\mathrm{NH}_{4}-\mathrm{G}\right)$, and hydrogen peroxide $\left(\mathrm{H}_{2} \mathrm{O}_{2}-\mathrm{G}\right)$ concentrations existing within each vertical grid cell for the standard and increased inputs at a model time of $540 \mathrm{~s}$, just before cloud formation. Pollutant concentrations in the grid for the increased input case are ten 
TABLE 4. MCCP PLUVIUS Output in Clear Air at Time $=540 \mathrm{~s}$ for (a) Base Case Inputs and (b) Base Case Inputs $\times 10$

(a) Base Case Inputs

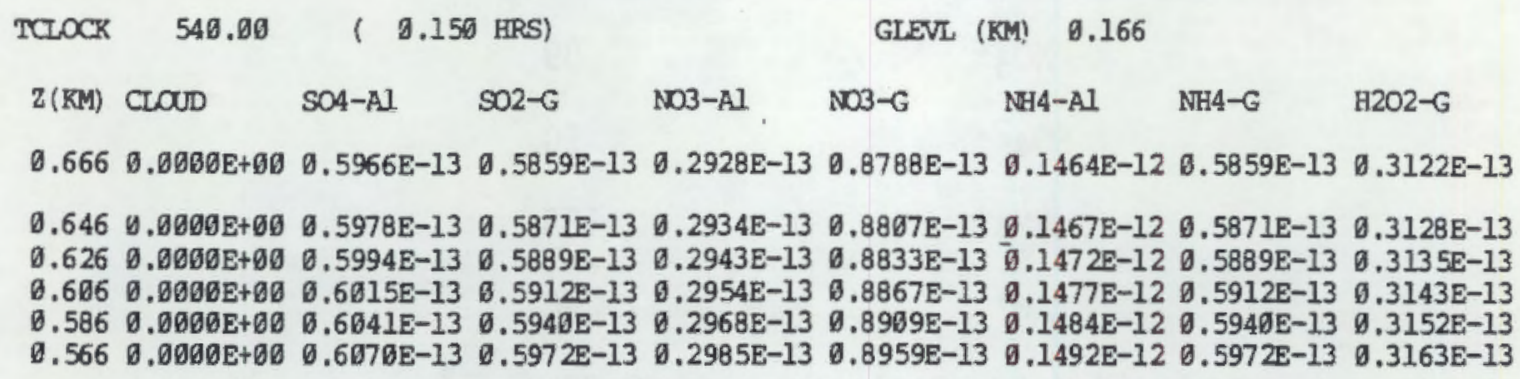

$0.546 \quad 0.0000 \mathrm{E}+\emptyset 0 \quad 0.6193 \mathrm{E}-13 \quad 0.6009 \mathrm{E}-13 \quad 0.3903 \mathrm{E}-13 \quad 0.9014 \mathrm{E}-13 \quad 0.1501 \mathrm{E}-12 \quad 0.6009 \mathrm{E}-13 \quad 0.3175 \mathrm{E}-13$ $0.5260 .0000 \mathrm{E}+00 \quad 0.6139 \mathrm{E}-13 \quad 0.6050 \mathrm{E}-13 \quad 0.3623 \mathrm{E}-13 \quad 0.9074 \mathrm{E}-13 \quad 0.1512 \mathrm{E}-12 \quad 0.6050 \mathrm{E}-13 \quad 0.3188 \mathrm{E}-13$ $0.506 \quad 0.0000 \mathrm{E}+96 \quad 0.6178 \mathrm{E}-13 \quad 0.6093 \mathrm{E}-13 \quad 0.3045 \mathrm{E}-13 \quad 0.9139 \mathrm{E}-13 \quad 0.1522 \mathrm{E}-12 \quad 0.6693 \mathrm{E}-13 \quad 0.3202 \mathrm{E}-13$

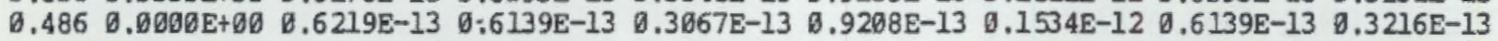

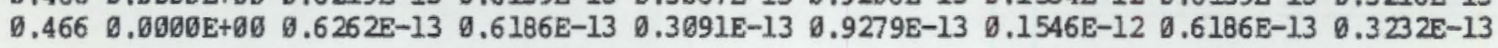

$0.446 \quad 0.0009 \mathrm{E}+\emptyset \emptyset \quad 0.6306 \mathrm{E}-13 \quad 0.6236 \mathrm{E}-13 \quad 0.3116 \mathrm{E}-13 \quad 0.9323 \mathrm{E}-13 \quad 0.1558 \mathrm{E}-12 \quad 0.6236 \mathrm{E}-13 \quad 0.3248 \mathrm{E}-13$ $0.426 \quad 0.0600 \mathrm{E}+00 \quad 0.6352 \mathrm{E}-13 \quad 0.6286 \mathrm{E}-13 \quad 0.3141 \mathrm{E}-13 \quad 0.9429 \mathrm{E}-13 \quad 0.1571 \mathrm{E}-12 \quad 0.6286 \mathrm{E}-13 \quad 0.3264 \mathrm{E}-13$

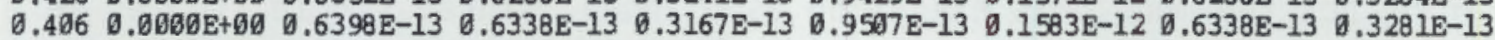
$0.386 \quad 0 . \emptyset 00 \emptyset \mathrm{E}+\emptyset \emptyset \quad 0.6446 \mathrm{E}-13 \quad 0.6390 \mathrm{E}-13 \quad 0.3193 \mathrm{E}-13 \quad 0.9586 \mathrm{E}-13 \quad 0.1597 \mathrm{E}-12 \quad 0.6390 \mathrm{E}-13 \quad 0.3298 \mathrm{E}-13$ $0.366 \quad 0.06 \emptyset 6 \mathrm{E}+\emptyset \emptyset \quad 0.6493 \mathrm{E}-13 \quad 0.6443 \mathrm{E}-13 \quad 0.3219 \mathrm{E}-13 \quad 0.9665 \mathrm{E}-13 \quad 0.1610 \mathrm{E}-12 \quad 0.6443 \mathrm{E}-13 \quad 0.3316 \mathrm{E}-13$

$0.346 \quad 0.0690 \mathrm{E}+\emptyset \mathrm{0} \quad 0.654 \mathrm{IE}-13 \quad 0.6496 \mathrm{E}-13 \quad 0.3246 \mathrm{E}-13 \quad 0.9744 \mathrm{E}-13 \quad 0.1623 \mathrm{E}-12 \quad 0.6496 \mathrm{E}-13 \quad 0.3334 \mathrm{E}-13$ $0.326 \quad 0.0000 \mathrm{E}+80 \quad 0.6588 \mathrm{E}-13 \quad 0.6548 \mathrm{E}-13 \quad 0.3272 \mathrm{E}-13 \quad 0.9822 \mathrm{E}-13 \quad 0.1636 \mathrm{E}-12 \quad 0.6548 \mathrm{E}-13 \quad 0.3351 \mathrm{E}-13$

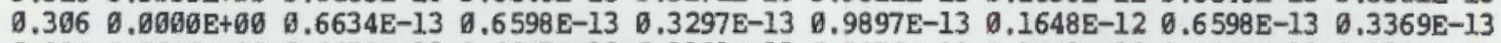

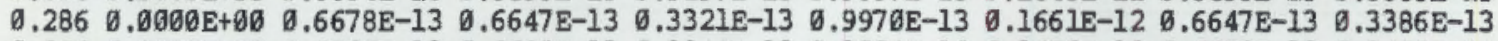
$0.266 \quad 0 . \emptyset 00 \emptyset \mathrm{E}+\emptyset \emptyset \quad 0.6728 \mathrm{E}-13 \quad 0.6692 \mathrm{E}-13 \quad 0.3344 \mathrm{E}-13 \quad 0.1004 \mathrm{E}-12 \quad 0.1672 \mathrm{E}-12 \quad 0.6692 \mathrm{E}-13 \quad 0.3402 \mathrm{E}-13$

$0.246 \quad 0.0009 \mathrm{E}+\emptyset \emptyset \quad 0.6758 \mathrm{E}-13 \quad 0.6734 \mathrm{E}-13 \quad 0.3365 \mathrm{E}-13 \quad 0.1010 \mathrm{E}-12 \quad 0.1682 \mathrm{E}-12 \quad 0.6734 \mathrm{E}-13 \quad 0.3417 \mathrm{E}-13$ $0.226 \quad 0.6000 \mathrm{E}+00 \quad 0.6793 \mathrm{E}-13 \quad 0.6771 \mathrm{E}-13 \quad 0.3383 \mathrm{E}-13 \quad 0.1016 \mathrm{E}-12 \quad 0.1692 \mathrm{E}-12 \quad 0.6771 \mathrm{E}-13 \quad 0.3431 \mathrm{E}-13$ $0.266 \quad 0.0006 \mathrm{E}+00 \quad 0.6822 \mathrm{E}-13 \quad 0.6802 \mathrm{E}-13 \quad 0.3399 \mathrm{E}-13 \quad 0.1020 \mathrm{E}-12 \quad 0.1699 \mathrm{E}-12 \quad 0.6802 \mathrm{E}-13 \quad 0.3443 \mathrm{E}-13$

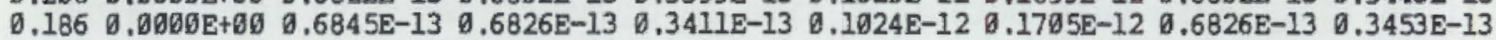
$\emptyset .166 \quad 0.6 \boxminus \boxminus 0 \mathrm{E}+\emptyset \emptyset \quad 0.6861 \mathrm{E}-13 \quad 0.6842 \mathrm{E}-13 \quad 0.3419 \mathrm{E}-13 \quad 0.1026 \mathrm{E}-12 \quad 0.1709 \mathrm{E}-12 \quad 0.6842 \mathrm{E}-13 \quad 0.3460 \mathrm{E}-13$

COLUMN MASS TOTALS (NOL/CM2) : SO2G $=0.3196 \mathrm{E}-98 \quad$ SO4AI $=0.2444 \mathrm{E}-09 \quad \mathrm{NO} \mathrm{Al}=0.4793 \mathrm{E}-09 \quad \mathrm{NOBG}=\emptyset .3666 \mathrm{E}-09$

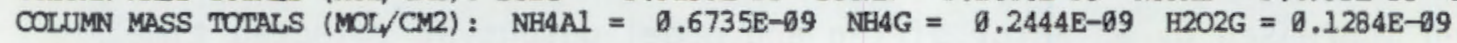




\section{TABLE 4. (Continued)}

(b) Base Case Inputs $\times 10$

TCIOCK $540.00 \quad(0.150$ HRS $\mathrm{Z}(\mathrm{KM}) \mathrm{CLOND} \quad \mathrm{SO}-\mathrm{Al} \quad \mathrm{SO}-\mathrm{G}$ $0.666 \quad 0.0605 \mathrm{E}+00 \quad 0.5966 \mathrm{E}-12 \quad 0.5859 \mathrm{E}-12 \quad 0.2928 \mathrm{E}-12 \quad 0.8788 \mathrm{E}-12 \quad 0.1464 \mathrm{E}-11 \quad 0.5859 \mathrm{E}-12 \quad 0.3122 \mathrm{E}-12$

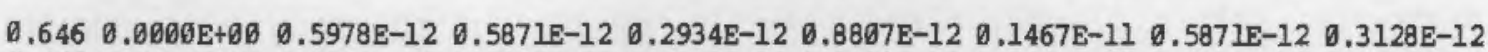

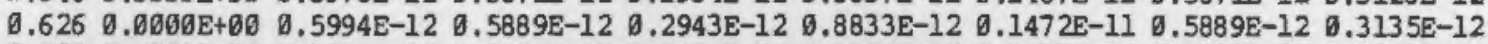
$0.686 \quad 0.0000 \mathrm{E}+00 \quad 0.6015 \mathrm{E}-12 \quad 0.5912 \mathrm{E}-12 \quad 0.2954 \mathrm{E}-12 \quad 0.8867 \mathrm{E}-12 \quad 0.1477 \mathrm{E}-11 \quad 0.5912 \mathrm{E}-12 \quad 0.3143 \mathrm{E}-12$ $0.586 \quad 0.0000 \mathrm{E}+00 \quad 0.6041 \mathrm{E}-12 \quad 0.5940 \mathrm{E}-12 \quad 0.2968 \mathrm{E}-12 \quad 0.8909 \mathrm{E}-12 \quad 0.1484 \mathrm{E}-11 \quad 0.5940 \mathrm{E}-12 \quad 0.3152 \mathrm{E}-12$ b.566 $0.60 \emptyset \boxminus \mathrm{E}+\emptyset \emptyset \quad 0.6070 \mathrm{E}-12 \quad 0.5972 \mathrm{E}-12 \quad 0.2985 \mathrm{E}-12 \quad 0.8959 \mathrm{E}-12 \quad 0.1492 \mathrm{E}-11 \quad 0.5972 \mathrm{E}-12 \quad 0.3163 \mathrm{E}-12$

$0.546 \quad 0.0000 \mathrm{E}+\emptyset 0 \quad 0.6193 \mathrm{E}-12 \quad 0.6009 \mathrm{E}-12 \quad 0.3003 \mathrm{E}-12 \quad 0.9014 \mathrm{E}-12 \quad 0.1501 \mathrm{E}-11 \quad 0.6509 \mathrm{E}-12 \quad 0.3175 \mathrm{E}-12$

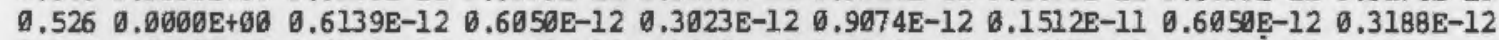
$0.506 \quad 0.0000 \mathrm{E}+\emptyset 00.6178 \mathrm{E}-12 \quad 0.6093 \mathrm{E}-12 \quad 0.3045 \mathrm{E}-12 \quad 0.9139 \mathrm{E}-12 \quad 0.1522 \mathrm{E}-11 \quad 0.6093 \mathrm{E}-12 \quad 0.3202 \mathrm{E}-12$ $0.486 \quad 0.0000 \mathrm{E}+\emptyset 0 \quad 0.6219 \mathrm{E}-12 \quad 0.6139 \mathrm{E}-12 \quad 0.3067 \mathrm{E}-12 \quad 0.9208 \mathrm{E}-12 \quad 0.1534 \mathrm{E}-11 \quad 0.6139 \mathrm{E}-12 \quad 0.3216 \mathrm{E}-12$ $0.466 \quad 0.0000 \mathrm{E}+\emptyset \emptyset \quad 0.6262 \mathrm{E}-12 \quad 0.6186 \mathrm{E}-12 \quad 0.3691 \mathrm{E}-12 \quad 0.9279 \mathrm{E}-12 \quad 6.1546 \mathrm{E}-11 \quad 0.6186 \mathrm{E}-12 \quad 0.3232 \mathrm{E}-12$

$0.446 \quad 0.0600 \mathrm{E}+\emptyset 0 \quad 0.6366 \mathrm{E}-12 \quad 0.6236 \mathrm{E}-12 \quad 0.3116 \mathrm{E}-12 \quad 0.9353 \mathrm{E}-12 \quad 0.1558 \mathrm{E}-11 \quad 0.6236 \mathrm{E}-12 \quad 0.3248 \mathrm{E}-12$ $0.426 \quad 0.0000 \mathrm{E}+00 \quad 0.6352 \mathrm{E}-12 \quad 0.6286 \mathrm{E}-12 \quad 0.3141 \mathrm{E}-12 \quad 0.9429 \mathrm{E}-12 \quad 0.1571 \mathrm{E}-11 \quad 0.6286 \mathrm{E}-12 \quad 0.3264 \mathrm{E}-12$ $0.406 \quad 0.0000 \mathrm{E}+00 \quad 0.6398 \mathrm{E}-12 \quad 0.6338 \mathrm{E}-12 \quad 0.3167 \mathrm{E}-12 \quad 0.9507 \mathrm{E}-12 \quad 0.1583 \mathrm{E}-11 \quad 0.6338 \mathrm{E}-12 \quad 0.3281 \mathrm{E}-12$ $0.386 \quad 0.0000 \mathrm{E}+00 \quad 0.6446 \mathrm{E}-12 \quad 0.6399 \mathrm{E}-12 \quad 0.3193 \mathrm{E}-12 \quad 0.9586 \mathrm{E}-12 \quad 0.1597 \mathrm{E}-11 \quad 0.6390 \mathrm{E}-12 \quad 0.3298 \mathrm{E}-12$ $0.366 \quad 0.0000 \mathrm{E}+\emptyset \emptyset \quad 0.6493 \mathrm{E}-12 \quad 0.6443 \mathrm{E}-12 \quad 0.3219 \mathrm{E}-12 \quad 0.9665 \mathrm{E}-12 \quad 0.1610 \mathrm{E}-11 \quad 0.6443 \mathrm{E}-12 \quad 0.3316 \mathrm{E}-12$

$0.346 \quad 0.0060 \mathrm{E}+60 \quad 0.6541 \mathrm{E}-12 \quad 0.6496 \mathrm{E}-12 \quad 0.3246 \mathrm{E}-12 \quad 0.9744 \mathrm{E}-12 \quad 0.1623 \mathrm{E}-11 \quad 0.6496 \mathrm{E}-12 \quad 0.3334 \mathrm{E}-12$

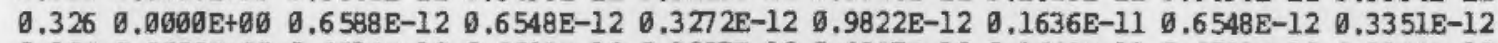
$0.306 \quad 0.0000 \mathrm{E}+060.6634 \mathrm{E}-12 \quad 0.6598 \mathrm{E}-12 \quad 0.3297 \mathrm{E}-12 \quad 0.9897 \mathrm{E}-12 \quad 0.1648 \mathrm{E}-11 \quad 0.6598 \mathrm{E}-12 \quad 0.3369 \mathrm{E}-12$

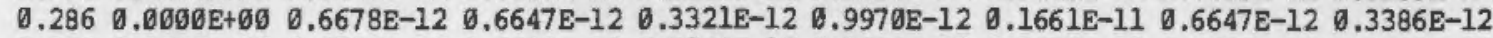
$0.266 \quad 0 . \emptyset \varpi \varpi \boxminus \mathrm{E}+\emptyset \emptyset \quad 0.6720 \mathrm{E}-12 \quad 6.6692 \mathrm{E}-12 \quad 0.3344 \mathrm{E}-12 \quad 0.1004 \mathrm{E}-11 \quad 0.1672 \mathrm{E}-11 \quad 0.6692 \mathrm{E}-12 \quad 0.3462 \mathrm{E}-12$

$0.246 \quad 0.6000 \mathrm{E}+06 \quad 0.6758 \mathrm{E}-12 \quad 0.6734 \mathrm{E}-12 \quad 6.3365 \mathrm{E}-12 \quad 0.1010 \mathrm{E}-11 \quad 0.1682 \mathrm{E}-11 \quad 0.6734 \mathrm{E}-12 \quad 0.3417 \mathrm{E}-12$ $0.226 \quad 0.0600 \mathrm{E}+00 \quad 0.6793 \mathrm{E}-12 \quad 0.6771 \mathrm{E}-12 \quad 0.3383 \mathrm{E}-12 \quad 0.1016 \mathrm{E}-11 \quad 0.1692 \mathrm{E}-11 \quad 0.6771 \mathrm{E}-12 \quad 0.3431 \mathrm{E}-12$

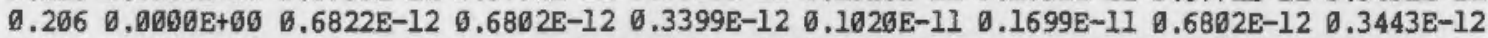
$0.186 \quad 0.0000 \mathrm{E}+06 \quad 0.6845 \mathrm{E}-12 \quad 0.6826 \mathrm{E}-12 \quad 0.3411 \mathrm{E}-12 \quad 6.1024 \mathrm{E}-11 \quad 0.1705 \mathrm{E}-11 \quad 0.6826 \mathrm{E}-12 \quad 0.3453 \mathrm{E}-12$ $0.166 \quad 0.0600 \mathrm{E}+66 \quad 0.6861 \mathrm{E}-12 \quad 6.6842 \mathrm{E}-12 \quad 6.3419 \mathrm{E}-12 \quad 0.1026 \mathrm{E}-11 \quad 0.1769 \mathrm{E}-11 \quad 0.6842 \mathrm{E}-12 \quad 0.3460 \mathrm{E}-12$

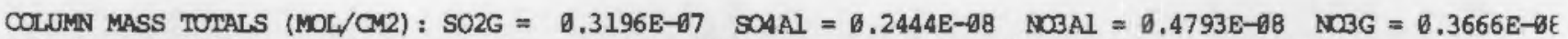
COLUN MASS TOTALS (MOL/CM2): NHAAL $=0.6735 \mathrm{E}-98 \quad \mathrm{NHAG}=0.2444 \mathrm{E}-8 \mathrm{~B} \quad \mathrm{HZO2G}=0.1284 \mathrm{E}-68$ 
times those for the base case, as they should be. Column mass totals also differ by a factor of ten, as they should.

\subsubsection{Solubility Comparison}

In the solubility comparison check, tests were conducted to check the performance of the model in computing the equilibrium $\mathrm{SO}_{2}$ solubility. Several runs were made with different cloud-water $\mathrm{pH}$ values and the resulting gas-cloud partitioning compared to the theoretical pH-dependent partitioning calculated from Hales and Sutter (1973). Model predictions and theoretical calculations were in good agreement.

\subsubsection{Mass Balance Check}

In the mass balance check, the degree of mass conservation within the model was determined. The conservation equation for a pollutant species within an air column lifted over a mountain as shown in Figure 5 can be expressed in general terms as

(Windward Inflow) - (Leeward Outflow) - (Deposition to the Surface) + (Net Gain from Chemical Reaction and Scavenging) $=0$

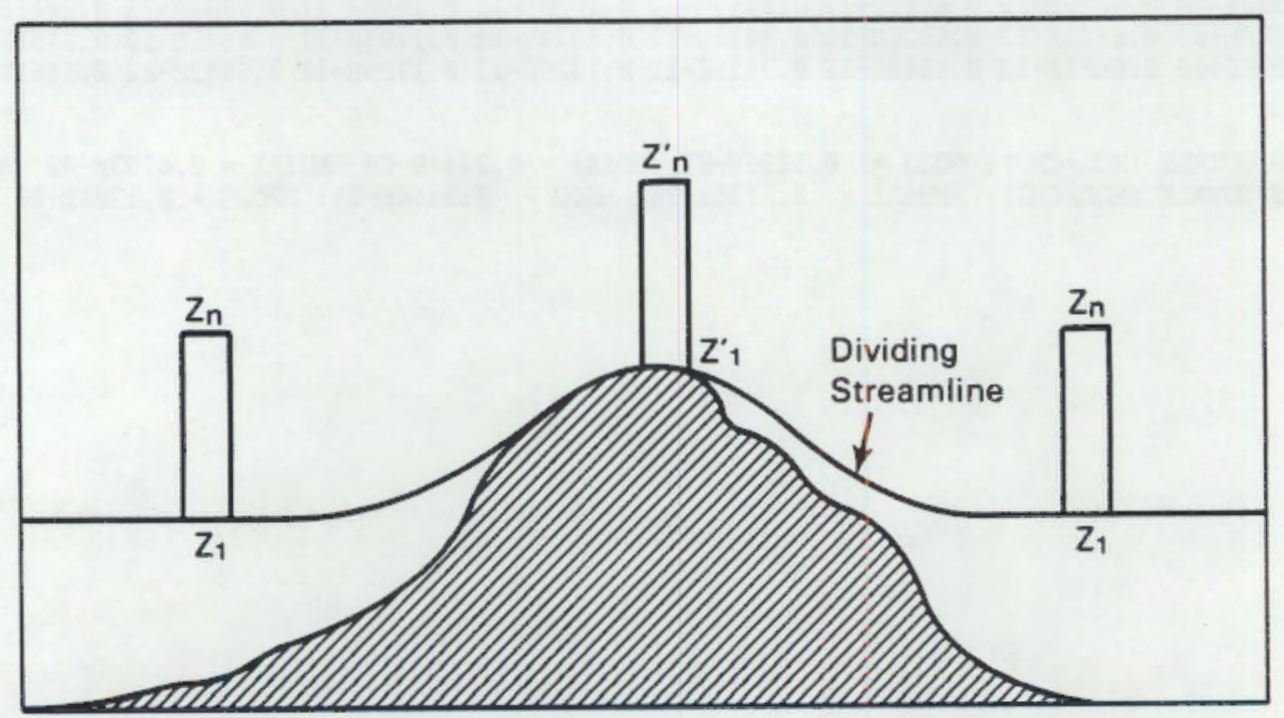

FIGURE 5. Schematic Representation of the Lifting of an Air Parcel 
Two assumptions are included in the above formulation: (1) pollutant flux across the top boundary is zero and (2) changes due to the air parcel rising and then descending to an equivalent position will balance.

By considering a group of species for which net chemical reaction and scavenging are zero (e.g., all nitrate species), the last term in Equation (8) vanishes and the conservation equation can be written

$$
\int_{z_{1}}^{z_{n}} u(z) C_{k}(z) d z=\int_{z i}^{z^{\prime} n} u(z) C_{k}(z) d z+\int_{t}^{t^{\prime}} v_{d}\left(u_{z 0}\right) c_{k}\left(z_{0}\right) u\left(z_{0}\right) d t
$$

where $\quad u(z)=$ horizontal wind velocity at height $z\left(\mathrm{~cm} \mathrm{~s}^{-1}\right)$

$$
\begin{aligned}
C_{k}(z)= & \text { concentration of species group } k \text { at height } z \text { (mol cm-3 space) } \\
v_{d}\left(u_{z o}\right)= & \text { cloud droplet deposition velocity at local ground height, } \\
& \text { which is a function of } u \text { at } z=z_{0}(\mathrm{~cm} \mathrm{~s}-1) \\
C_{k}\left(z_{0}\right)= & \text { concentration of specie group } k \text { at local ground height } \\
& \text { (mol cm-3 space) } \\
u\left(z_{0}\right)= & \text { horizontal wind velocity at local ground height } z_{0}\left(\mathrm{~cm} \mathrm{~s}^{-1}\right) \\
t= & \text { time corresponding to the air column position } z_{1}, z_{n} \\
t^{\prime}= & \text { time corresponding to the air column position } z_{1}^{1}, z_{n}^{1}
\end{aligned}
$$

Note that the last term is the horizontal integral $\left[\mathrm{dx}=u\left(z_{0}\right) \cdot d t\right]$ of the deposition rate.

A mass balance for the system based on Equation (9) can thus be expressed as

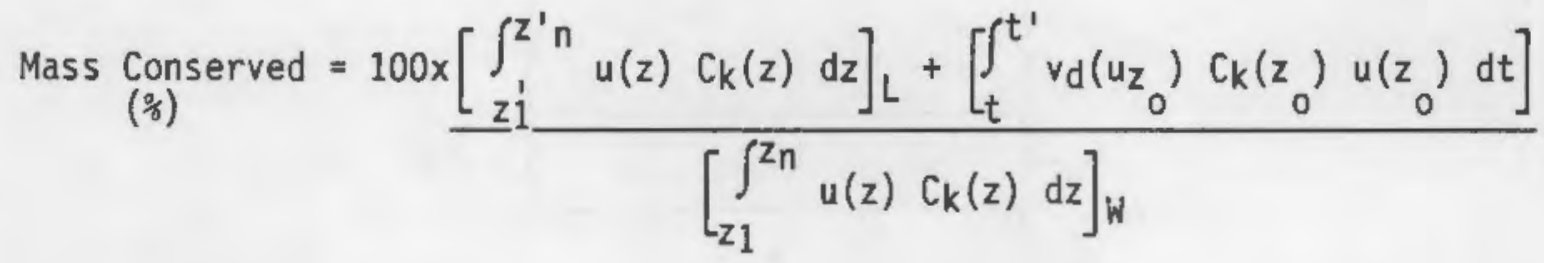

where the second integral in the numerator represents the cumulative deposition of a pollutant to the mountain surface and the subscripts $L$ and $W$ denote leeward and windward quantities. Values near $100 \%$ for the mass-conservation quantity 
indicate that integration algorithms within the code are adequately handling the numerics of the situation being modeled.

In the current application of MCCP PLUVIUS, wind speed is constant with altitude and can be eliminated from the above equations. The total depth of the air column and the spacing of intermediate grid cells also remain constant, with only the level of the column base changing. Under these conditions, and recognizing that MCCP PLUVIUS output represents the concentration at the midpoint of a grid cell (see Figure 6), the windward and leeward integrals given in Equation (10) can be approximated by

$$
{ }_{z 1} \int^{z n} C_{k}(z) d z=\sum_{i=2}^{n-1}\left(C_{i k} \Delta z\right)+0.5 \Delta z\left(C_{1 k}+C_{n k}\right)
$$

where $C_{i k}$ is the concentration of species $k$ within grid cell $i$ and $\Delta z$ is the grid spacing. In the current application, $n$ equals 26 and $\Delta z$ is $20 \mathrm{~m}$.

Note that Equation (11) yields the total pollutant mass within the modeled air column in moles per square centimeter of space and is a valid approximation

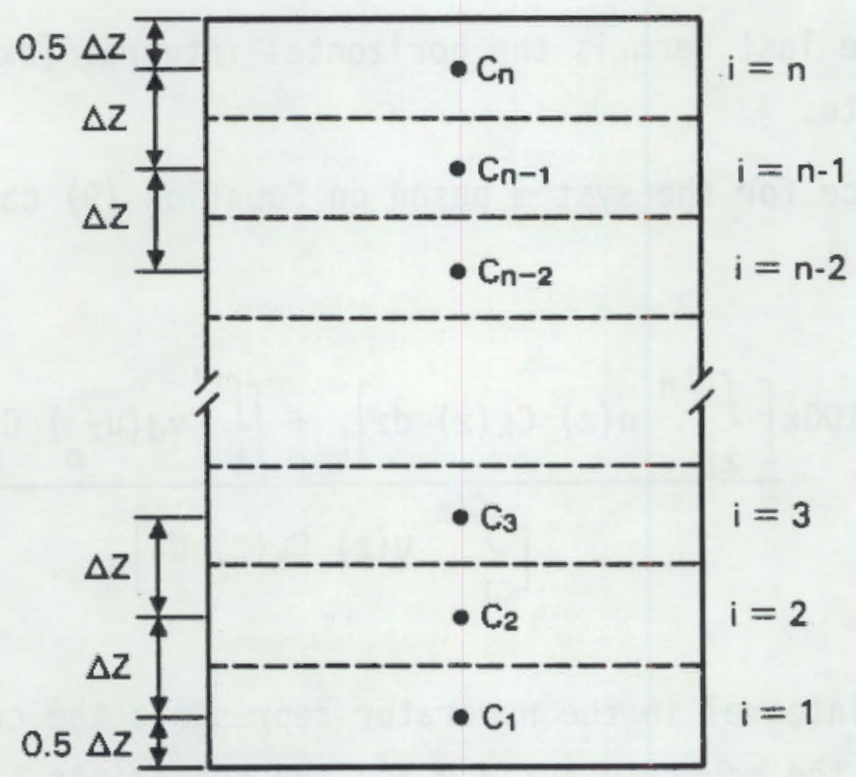

FIGURE 6. Grid Cell Spacing Within an MCCP PLUVIUS Air Column 
to the windward and leeward integrals in Equation (10) only in the case of constant wind speed. For wind shear situations, u remains a function of $z$ and cannot be eliminated from Equation (10). In such cases, the integrals of Equation (10) must be maintained and the individual components of the mass conservation equation calculated in moles per centimeter per second.

As an air parcel rises, its density changes. With the "rigid" grid imposed on the air column, this requires concurrent changes in concentration. This situation can be visualized as pollutant flowing perpendicularly from Figure 5 (into and out of the page) along a non-modelled spatial axis. As the air parcel descends, air density increases and pollutant will be "drawn back" into the grid. However, if the lifting motion produces a cloud, pollutants are lost by deposition and there is less total pollutant on the leeward side to be "drawn in." To maintain the second assumption used in formulating the conservation equation, it is necessary to choose inflow and outflow clear-air positions such that air densities within the respective grid cells are equal. This situation occurs at model times of 540 and $1110 \mathrm{~s}$, where air densities at the grid midpoint differ by less than $0.03 \%$. Equation (11) was thus applied to model results for times of 540 and $1110 \mathrm{~s}$ in all mass balance calculations.

Table 5 summarizes the inflow, cumulative deposition, and outflow quantities calculated using Equations (10) and (11) for the major sulfur- and nitrogen-containing species modeled by MCCP PLUVIUS. The quantity "total sulfur" refers to the sum of all sulfur-containing species [ $\mathrm{SO}_{4}{ }^{2-}, \mathrm{SO}_{2}$, and hydroxymethane sulfonate (HMSA)] existing in the various aerosol, aqueous, and gaseous states. Similarly, "total nitrate" and "total ammonium" refer to the sum of nitrate and ammonium in the aerosol, aqueous, and gaseous states.

As can be seen in this table, the mass loss calculated for these major species is less than $0.7 \%$ for the base case. Since the value selected for cloud-droplet deposition velocity will affect cumulative deposition totals, and thus mass conservation within the model, percentage losses for two other $v_{d}$ values are also presented. The two $v_{d}$ values selected (28 and $112 \mathrm{~cm} \mathrm{~s}-1$ ) represent half and twice the base case value of $56 \mathrm{~cm} \mathrm{~s}^{-1}$. In all cases, mass is adequately conserved within the model. 
TABLE 5. Mass Conservation Within MCCP PLUVIUS for Base Case Inputs and Three Deposition velocities $\left(v_{d}\right)$

\begin{tabular}{|c|c|c|c|c|c|c|c|c|}
\hline \multicolumn{3}{|c|}{$v_{d}=56 \mathrm{~cm} \mathrm{~s}^{-1}(a)$} & \multicolumn{3}{|c|}{$v_{d}=28 \mathrm{~cm} \mathrm{~s}^{-1}$} & \multicolumn{3}{|c|}{$v_{d}=112 \mathrm{~cm} \mathrm{~s}^{-1}$} \\
\hline $\begin{array}{l}\text { Total } \\
\text { Sulfur }\end{array}$ & $\begin{array}{c}\text { Total } \\
\text { Nitrate }\end{array}$ & $\begin{array}{c}\text { Total } \\
\text { Ammonium }\end{array}$ & $\begin{array}{l}\text { Total } \\
\text { Sulfur }\end{array}$ & $\begin{array}{l}\text { Total } \\
\text { Nitrate } \\
\end{array}$ & $\begin{array}{c}\text { Total } \\
\text { Ammonium }\end{array}$ & $\begin{array}{l}\text { Total } \\
\text { Sulfur }\end{array}$ & $\begin{array}{l}\text { Total } \\
\text { Nitrate } \\
\end{array}$ & $\begin{array}{c}\text { Total } \\
\text { Ammonium }\end{array}$ \\
\hline 6.358 & 6.325 & 11.07 & 6.358 & 6.325 & 11.07 & 6.358 & 6.325 & 11.07 \\
\hline 0.370 & 0.704 & 1.231 & 0.306 & 0.574 & 1.004 & 0.387 & 0.733 & 1.281 \\
\hline 5.949 & 5.578 & 9.763 & 6.029 & 5.721 & 10.01 & 5.887 & 5.485 & 9.599 \\
\hline 99.4 & 99.3 & 99.3 & 99.6 & 99.5 & 99.5 & 98.7 & 98.3 & 98.3 \\
\hline
\end{tabular}

(a) $v_{d}$ value used in base case. 


\subsection{IMPLICATIONS OF BASE CASE RESULTS}

The mass balance approach discussed above can be expanded to examine the base case results more closely. For example, information on $\mathrm{SO}_{2}$ and HMSA inflow, deposition, and outflow can be used to determine the percentage of $\mathrm{SO}_{2}$ oxidized, using the mass balance equation

$\mathrm{SO}_{2} \underset{(\%)}{0 x i d i z e d}=100 x\left[1-\frac{\left(\mathrm{SO}_{2}\right)_{L}+\left(\mathrm{HMSA}_{\mathrm{L}} \mathrm{L}+\left(\mathrm{SO}_{2}\right)_{\mathrm{d}}+(\mathrm{HMSA}) \mathrm{d}\right.}{\left(\mathrm{SO}_{2}\right) \mathrm{W}+(\mathrm{HMSA}) \mathrm{W}}\right]$

where the subscripts $L, d$, and $W$ refer to the leeward, deposited, and windward quantities, respectively. Since mass losses within the model are not considered in the above equation, figures calculated with it represent the maximum percentage oxidation occurring within the modeled air column. Because Equation (12) is derived using the same mass balance approach discussed in Section 2.3.3, the windward and leeward quantities must be determined under conditions of equal air densities (e.g., model times of 540 and $1110 \mathrm{~s}$ ) and cumulative deposition must be employed.

Table 6 summarizes the information needed to determine the degree of $\mathrm{SO}_{2}$ oxidation within the base case model run. As shown there, only $4.7 \%$ of the inflow gaseous $\mathrm{SO}_{2}$ is oxidized to $\mathrm{SO}_{4}{ }^{2-}$. A very small amount $(0.2 \%)$ is deposited on the mountain as dissolved $\mathrm{SO}_{2}$ in the impacting cloud droplets, while the remaining $95.1 \%$ exists as either gaseous $\mathrm{SO}_{2}$ or aerosol HMSA on the

IABLE 6. In-Cloud $\mathrm{SO}_{2}$ Oxidation for the Base Case

\begin{tabular}{|c|c|c|c|}
\hline & $\mathrm{SO}_{4}^{2-(\mathrm{nmol} \mathrm{cm}-2)}$ & $\underline{\mathrm{SO}}_{2}\left(\mathrm{nmol} \mathrm{cm}^{-2}\right)$ & HMSA (nmol $\left.\mathrm{cm}^{-2}\right)$ \\
\hline Inflow & 3.196 & 3.162 & $3.203 \times 10^{-9}$ \\
\hline Deposition & 0.364 & 0.006 & 0 \\
\hline Outflow & 2.942 & 3.008 & $5.274 \times 10^{-5}$ \\
\hline
\end{tabular}

Inflow $\mathrm{SO}_{2}$ Oxidized to $\mathrm{SO}_{4}^{2-:}: 4.7 \%$

Inflow $\mathrm{SO}_{2}$ Deposited as Sulfur in the +4 Oxidation State: $0.2 \%$

Inflow $\mathrm{SO}_{2}$ Exiting as $\mathrm{SO}_{4}^{2-}$ : $95.1 \%$ 
leeward side of the mountain. While the fraction of $\mathrm{SO}_{2}$ oxidized to sulfate is relatively small, it must be remembered that the values are based on a mass balance approach for the entire air column. For the meteorological conditions simulated in the base case, the cloud extends a maximum of $200 \mathrm{~m}$ into the $500 \mathrm{~m}$ column domain; clear air exists in the remaining $300 \mathrm{~m}$ depth. Since the vertical pollutant profiles used to initialize the model produce higher pollutant concentrations at the bottom of the air column, this $200 \mathrm{~m}$ cloud exists in a region that holds approximately $45 \%$ of the total sulfur burden within the air column. Thus, inflow $\mathrm{SO}_{2}$ in the very upper portion of the air column simply passes over the mountain, never having the opportunity to undergo aqueous-phase oxidation since no liquid water exists. However, it must also be remembered that, in the portion of the air column where cloud does exist, the time available for oxidation is short; the meteorological conditions simulated in the base case lead to cloud droplet lifetimes that are on the order of $6 \mathrm{~min}$. Using this droplet lifetime leads to a minimum $\mathrm{SO}_{2}$ oxidation rate of $47 \% \mathrm{~h}-1$ for base case conditions within the entire air column.

A similar mass balance approach can be used to determine what effect cloud deposition has on other species within the air mass. Using the information presented in Table 5 for the base case $v_{d}$ of $56 \mathrm{~cm} \mathrm{~s}-1$, it can be seen that $88.2 \%$ of the nitrate and ammonium existing upwind of the mountain in the aerosol and gaseous states will also exist in the clear air on the lee side of the mountain. For all sulfur species, this figure rises to $93.6 \%$. In essence, the model indicates that, for the meteorological conditions simulated in the base case, most of the material existing in an air column before ascent and cloud formation will also exist in the air column after descent and cloud evaporation. 


\subsection{SENSITIVITY STUDIES}

The purpose of the sensitivity studies was to identify the meteorological and chemical input parameters in MCCP PLUVIUS that have the greatest impact on model output. By extension, the parameters identified in this study are likely to have a major influence on the cloud water chemistry observed at Mt. Mitchell. The following major questions were addressed in the sensitivity studies:

- Are deposition amounts and patterns strongly influenced by the value of cloud-droplet deposition rate?

- Does the turbulent-eddy diffusivity strongly influence deposition?

- For set humidity and temperature profiles, how do the concentration profiles of cloud water and pollutant chemicals in cloud water change as wind speed is changed? Are sulfate and hydrogen ion deposition amounts and patterns significantly affected?

- What effect does wind shear have on concentration profiles and deposition fluxes?

- How do various combinations of $\mathrm{H}_{2} \mathrm{O}_{2}$ and $\mathrm{SO}_{2}$ concentrations affect the degree of $\mathrm{SO}_{2}$ oxidation and the corresponding deposition of $\mathrm{H}^{+}$and $\mathrm{SO}_{4}{ }^{2-}$ ?

- To what degree does the concentration of pre-existing sulfate aerosol influence the amount of sulfate deposition? Does the overall degree of aerosol neutralization affect sulfate and hydrogen ion deposition?

- Does the presence of an acidifying gas, such as nitric acid ( $\mathrm{HNO}_{3}$ ), or a neutralizing gas, such as ammonia $\left(\mathrm{NH}_{3}\right)$, affect sulfate and hydrogen ion deposition? Are $\mathrm{SO}_{2}$ oxidation rates also affected?

- Does the initial gas/aerosol partitioning of nitrate and ammonium (a function of an air parcel's recent history) have a large effect on the total deposition of cloud-borne nitrogen compounds?

The first four of these questions concern the effects of meteorological parameters, while the remainder concern the effects of various chemical parameters. 


\subsection{VARIATION OF METEOROLOGICAL PARAMETERS}

\subsubsection{Deposition Velocity}

The value chosen for the deposition velocity $\left(v_{d}\right)$ affects the rate at which the cloud droplets are deposited out of the bottom of the air column to the surface of the mountain. The present version of MCCP PLUVIUS (Luecken et al. 1987) calculates deposition velocity as a linear function of horizontal wind speed using the method of Lovett and Reiners (1982). When the wind speed is $7.5 \mathrm{~m} \mathrm{~s}^{-1}, \mathrm{vd}_{\mathrm{d}}$ is $56 \mathrm{~cm} \mathrm{~s}^{-1}$. However, the actual value of $\mathrm{v} d_{d}$ should also be a function of surface roughness and drop-size distribution, among other factors, and many uncertainties exist in predictions of deposition velocities for different situations [see Lovett and Reiners (1982) for a comparison of experimental measurements].

To examine the effect of $v_{d}$ on pollutant deposition, model runs were made with three different $v_{d}$ values at a constant wind speed of $7.5 \mathrm{~m} \mathrm{~s}^{-1}$. Other meteorological variables (e.g., humidity profiles, temperature profiles) were the same as in the base case run. Figure 7 shows the cloud-water deposition rates obtained using $v_{d}$ values of $28 \mathrm{~cm} \mathrm{~s}^{-1}, 56 \mathrm{~cm} \mathrm{~s}^{-1}$ (base case), and $112 \mathrm{~cm} \mathrm{~s}^{-1}$. Although the amount of liquid water present in the cloud initially is the same for all runs, the simulation with the lowest $v_{d}$ is found to have the smallest cloud deposition rate because of the dependence of this rate on $v_{d}$ (see Section 2.2). Sulfate concentrations within the depositing cloud water are compared for all three $v_{d}$ values in Figure 8 . In contrast to the direct relationship observed between $v_{d}$ and cloud deposition rate in Figure 7, the curves in Figure 8 illustrate an inverse relationship; the higher the value of $v_{d}$, the lower the aqueous-phase pollutant concentration. This situation results from the greater depletion occurring at higher $v_{d}$ values; surface pollutant concentrations are limited by the turbulent transfer of material from higher in the cloud. Examination of the vertical concentration profiles for each of these runs verifies that the greater the value of $v_{d}$, the greater the degree of the pollutant depletion in the lower levels of the cloud.

Sulfate deposition fluxes for all three vd values are presented in Figure 9. The inverse interaction between cloud-water deposition rate and 


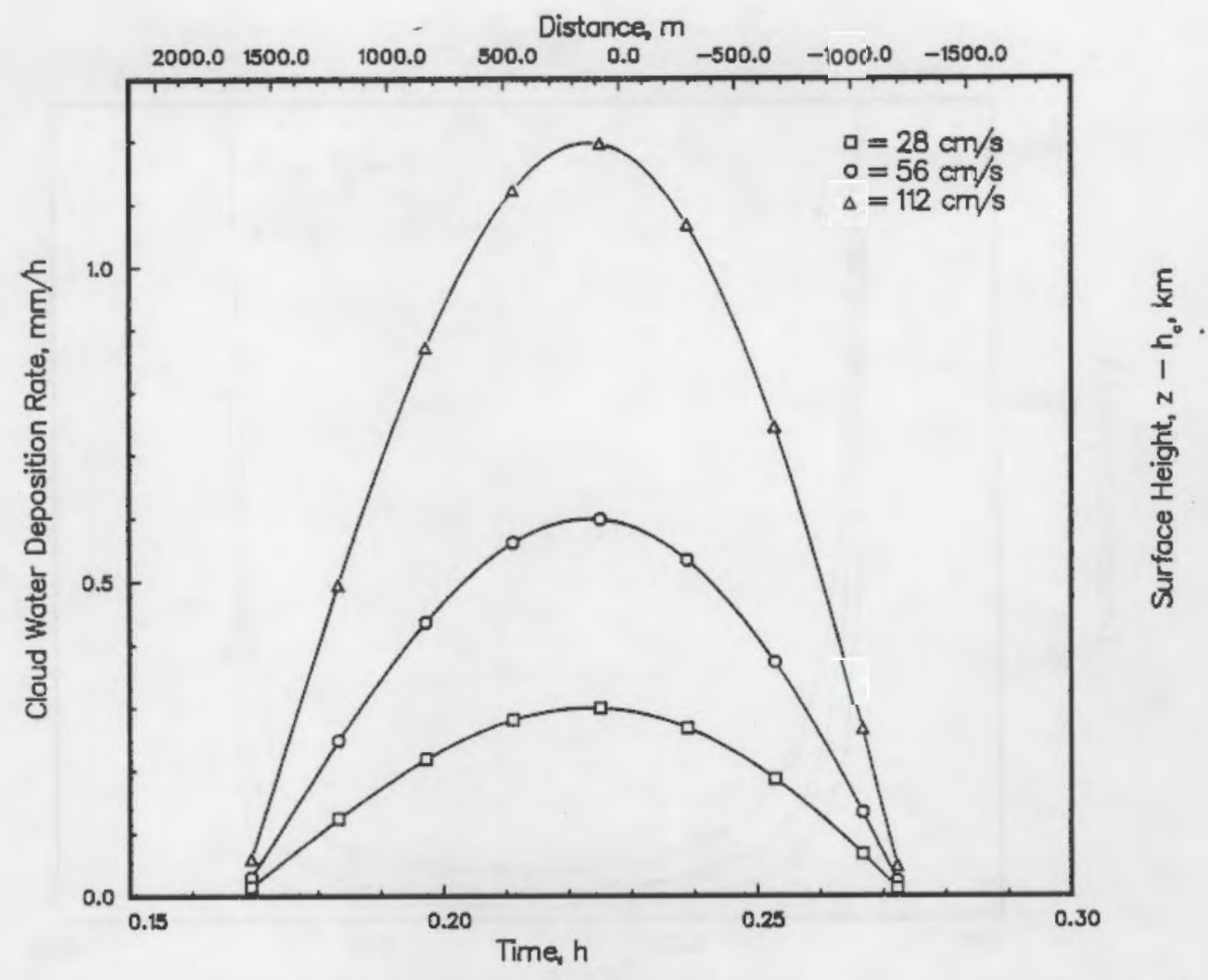

FIGURE 7. Cloud Water Deposition Rate for Various Values of $v_{d}$

aqueous-phase pollutant concentrations result in deposition fluxes that, after the first minute of cloud formation, vary only slightly for all three $v_{d}$ values.

Similarly, total deposition across the mountain does not vary substantially with changes in $v_{d}$. Table 7 summarizes the cumulative deposition amounts for the major ionic species. Note that the $300 \%$ increase in raising $v_{d}$ from 28 to $112 \mathrm{~cm} \mathrm{~s}^{-1}$ results in only a $21 \%$ increase in cumulative $504^{2-}$ - deposition, TABLE 7. Effect of Deposition Velocity on Cumulative Deposition. (Base
case values for initial pollutant species used in all runs.)

Deposition Velocity $\left(\mathrm{cm} \mathrm{s}^{-1}\right)$

28

56

112
Cumulative Deposition (nmol $\mathrm{cm}^{-2}$ )

$\mathrm{SO}_{4} 2_{-}^{-} \quad \mathrm{NO}_{3}^{-} \quad \mathrm{NH}_{-}^{+} \quad \underline{\mathrm{H}^{+}}$

$\begin{array}{llll}0.30 & 0.57 & 1.00 & 0.20 \\ 0.36 & 0.70 & 1.23 & 0.24 \\ 0.37 & 0.73 & 1.28 & 0.28\end{array}$




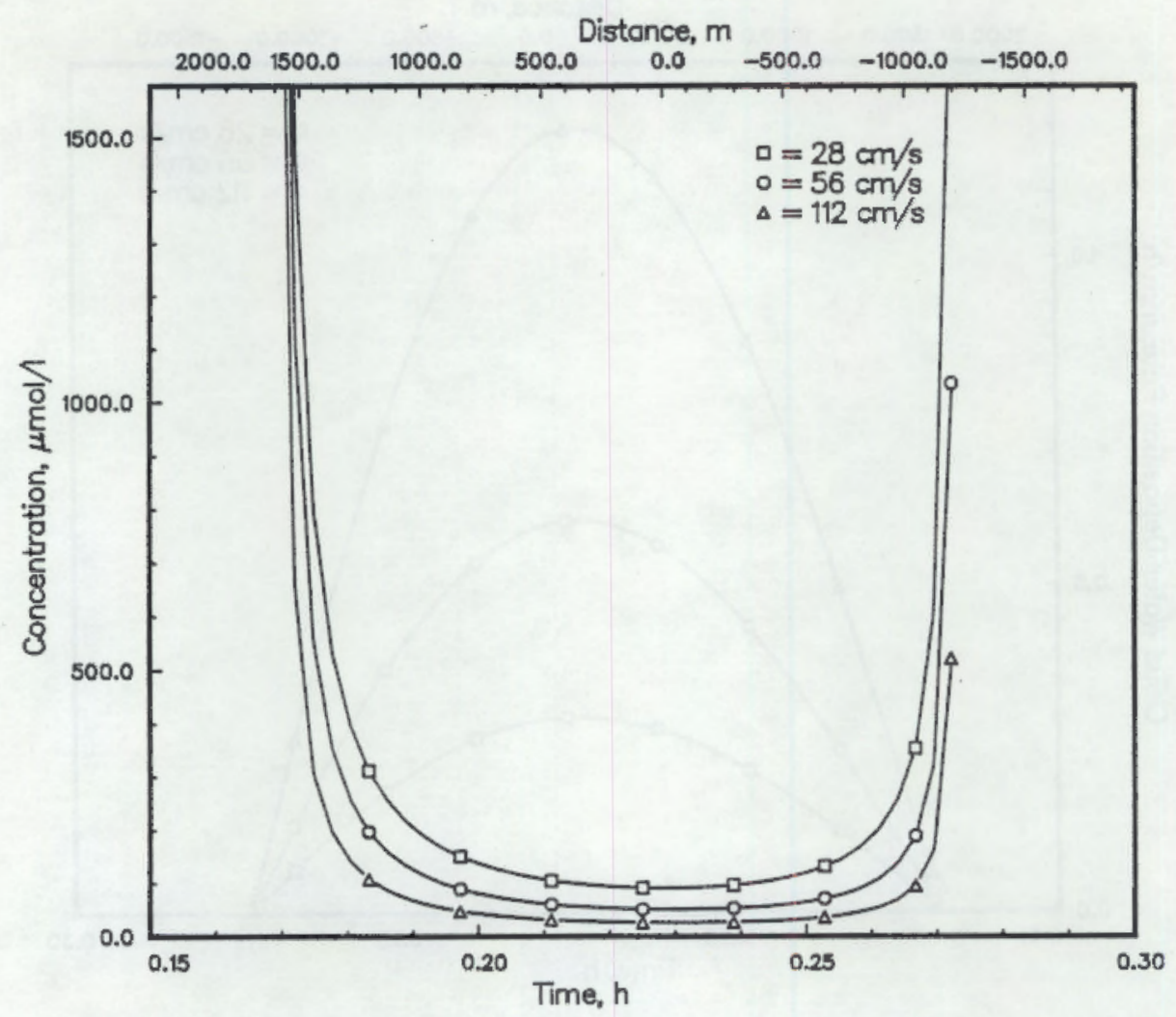

FIGURE 8. $\mathrm{SO}_{4}^{2-}$ Concentrations Within Depositing Cloud Water for Various Values of $v_{d}$

a $42 \%$ increase in $\mathrm{H}^{+}$deposition, and a $28 \%$ increase for both $\mathrm{NO}_{3}^{-}$and $\mathrm{NH}_{4}{ }^{+}$ deposition. These results suggest that total deposition in the base case simulation is not particularly sensitive to the exact linear relationship between wind speed and $v_{d}$ used in the model.

\subsubsection{Turbulent-Eddy Diffusivity}

As discussed in the previous section, pollutant depletion occurs in the lower levels of the cloud. Turbulent transport of pollutants among cloud layers within MCCP PLUVIUS is partly governed by the turbulent-eddy diffusivity. The current version of the model uses a mid-range value of $10^{5} \mathrm{~cm}^{2} \mathrm{~s}^{-1}$ forthis parameter. Although this is an accepted typical value for atmospheric work, little is known about eddy diffusivities within cap clouds in general or within specific Mt. Mitchell cloud events. To examine whether different values of eddy diffusivity influence deposition by affecting the "resupply" of pollutants in the lower levels of the the cloud, simulations were also performed with 


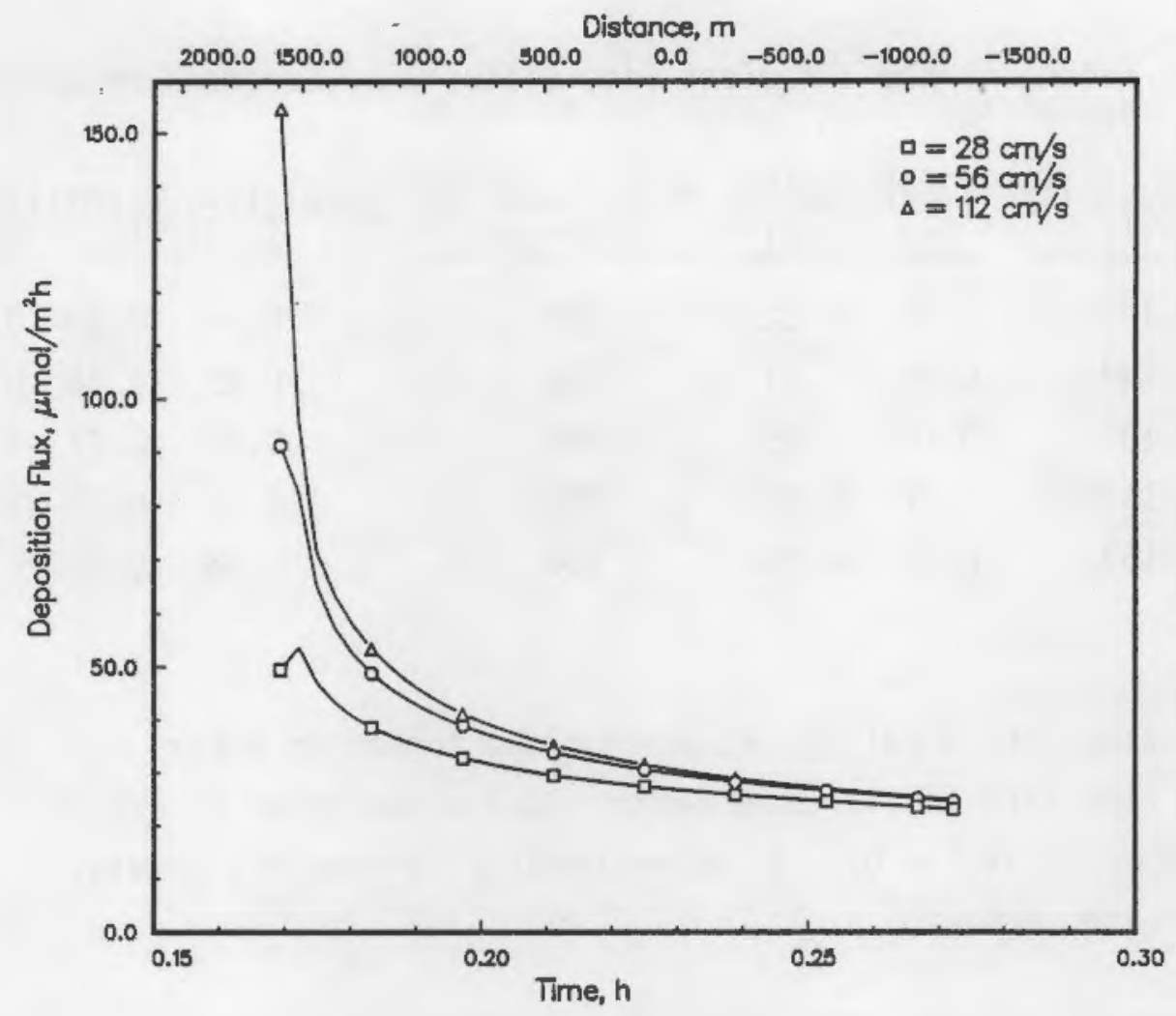

FIGURE 9. $\mathrm{SO}_{4}{ }^{2-}$ Deposition Flux for Various Values of $v_{d}$

eddy diffusivities of $10^{3}, 10^{4}, 5 \times 10^{4}$, and $2 \times 10^{5} \mathrm{~cm}^{2} \mathrm{~s}-1$. Other meteorological variables (wind speed, humidity and temperature profiles, $v_{d}$, etc.) were the same as in the base case run.

As shown by the sumnary in Table 8 , changes in the eddy diffusivity can affect cloud characteristics. With lower eddy diffusivities, there is less mixing of dry air outside the cloud with saturated air existing within the cloud. Therefore, the cloud forms earlier and lasts longer relative to the base case, providing more time for deposition to occur. However, because there is decreased transfer of pollutants to the lower cloud layer where deposition is occurring, cumulative deposition amounts do not change significantly. Similarly, with higher eddy diffusivities, the cloud exists for a shorter period of time and within a shallower layer relative to the base case. However, increased transfer within the cloud layers brings more pollutants to the cloud bottom, and cumulative deposition totals again do not change substantially. In short, changes in the eddy diffusivity create a 
TABLE 8. Effect of the Turbulent Eddy Diffusivity Constant on Cumulative Deposition

\begin{tabular}{|c|c|c|c|c|c|c|c|}
\hline $\begin{array}{l}\text { Eddy Diffusivity } \\
\left(\mathrm{cm}^{2} \mathrm{~s}^{-1}\right)\end{array}$ & $\begin{array}{l}t_{f}(a) \\
\text { (h) }\end{array}$ & $\begin{array}{l}t_{e}(b) \\
(h)\end{array}$ & $\begin{array}{l}\text { Max. Cloud (c) } \\
\text { Depth (m) }\end{array}$ & $\frac{\text { Cumulative }}{\underline{\mathrm{SO}^{2}} 4-}$ & $\frac{\text { Deposi }}{\text { N03:- }}$ & $\begin{array}{l}\text { tion } \\
\text { NH} 4_{-}^{+}\end{array}$ & $\frac{\left(\mathrm{nmol}_{\mathrm{cm}}^{-2}\right)}{\frac{\mathrm{H}^{+}}{4}}$ \\
\hline 1. $\times 10^{3}$ & 0.13 & 0.32 & 200 & 0.14 & 0.29 & 0.50 & 0.18 \\
\hline 1. $\times 10^{4}$ & 0.14 & 0.31 & 200 & 0.25 & 0.48 & 0.84 & 0.24 \\
\hline 5. $\times 10^{4}$ & 0.16 & 0.29 & 200 & 0.40 & 0.77 & 1.34 & 0.29 \\
\hline 1. $\times 105(d)$ & 0.17 & 0.27 & 200 & 0.36 & 0.70 & 1.23 & 0.24 \\
\hline 2. $\times 10^{5}$ & 0.20 & 0.24 & 160 & 0.28 & 0.56 & 0.98 & 0.16 \\
\hline
\end{tabular}

(a) $t_{f}=$ time into model run at which cloud formation occurs.

(b) $t_{e}=$ time into model run at which cloud evaporation occurs.

(c) Cloud depth at $t=0.23 \mathrm{~h}$, corresponding to mountain summit.

(d) Base case scenario.

trade-off between increased pollutant transfer and decreased cloud lifetime that produce only small changes in the cumulative pollutant deposition. As indicated by the trends in Table 8 , this trade-off leads in the base case scenario to maximum deposition occurring when the turbulent-eddy diffusivity constant is between $10^{4}$ and $10^{5} \mathrm{~cm}^{2} \mathrm{~s}-1$.

\subsubsection{Wind Speed}

The sensitivity of MCCP PLUVIUS to horizontal-wind-speed values is important to assess for two reasons: (1) substantial variations in wind speed are observed in nature and (2) two important variables within the model are direct functions of wind speed. As discussed in Section 3.1.1, the parameterization of $v_{d}$ includes a dependence on wind speed. Another quantity that is a direct function of the horizontal wind speed is the vertical velocity of the moist layer in an air column, which strongly influences cloud formation and evaporation within the model. This dependence is a result of the dividing streamline approach used in determining the surface along which an approaching air column will travel during its passage over the mountain [see Luecken et al. (1987) for a detailed discussion]. Thus, an event with a wind speed of $10 \mathrm{~m} \mathrm{~s}^{-1}$ 
may have a surface profile very different from that of an event with a wind speed of $7.5 \mathrm{~m} \mathrm{~s}^{-1}$.

MCCP PLUVIUS runs were made using horizontal-wind-speed values of 5.0, 7.5 (base case), and $10.0 \mathrm{~m} \mathrm{~s}^{-1}$ to determine the effect of this input variable on the total deposition of cloud-borne pollutants to the mountain surface. Parameterizations for the dividing streamline surface corresponding to these wind speeds were derived using the approach described by Luecken et al. (1987, Chapter 3). Values for variables that are functions of wind speed, such as $v_{d}$, were automatically adjusted within the model. A turbulent-eddy diffusivity of $10^{5} \mathrm{~cm}^{2} \mathrm{~s}^{-1}$ was used. All other input variable values were equal to the base case inputs listed in Table 1.

The model run with an input wind speed of $5 \mathrm{~m} \mathrm{~s}^{-1}$ failed to generate a cap cloud. In this case, the moist layer was below the critical dividing streamline height and the shallow layer lifted over the mountain was too dry to form a cloud. Results for an input horizontal wind speed of $7.5 \mathrm{~m} \mathrm{~s}-1$ have been discussed in detail in Chapter 2 of this report. When the wind speed was increased to $10 \mathrm{~m} \mathrm{~s}-1$, the cloud formed earlier in the event and had a larger liquid water concentration, and the column contained cloudy air for a longer time than in the base case, as shown in Figure 10. As a result, more than twice as much total cloud water was deposited on the mountain surface at $10 \mathrm{~m} \mathrm{~s}^{-1}$ as at $7.5 \mathrm{~m} \mathrm{~s}^{-1}$. Given that the initial clear-air pollutant concentrations were the same for both model runs, greater dilution pollutants occurred in the cloud water for the $10 \mathrm{~m} \mathrm{~s}^{-1}$ case. Chemical concentrations for this run are about half those predicted in the base case, as shown in Figure 11. However, the combination of greater cloud-water deposition and smaller pollutant concentrations balance so that the pollutant deposition flux is approximately the same for both wind speeds, as can be seen by comparing Figures 4 and 12 .

Over the entire mountain surface, the higher wind speed of $10 \mathrm{~m} \mathrm{~s}-1$ produced a 16 to $30 \%$ larger cumulative deposition of all pollutant species except S(IV), as compared to the base case. For S(IV), the deposition was over four times larger. The greater S(IV) deposition is a consequence of higher dissolved S(IV) concentrations, which in turn resuited from the greater dissolution of $\mathrm{SO}_{2}$. More $\mathrm{SO}_{2}$ went into solution for the $10 \mathrm{~m} \mathrm{~s}^{-1}$ case because 


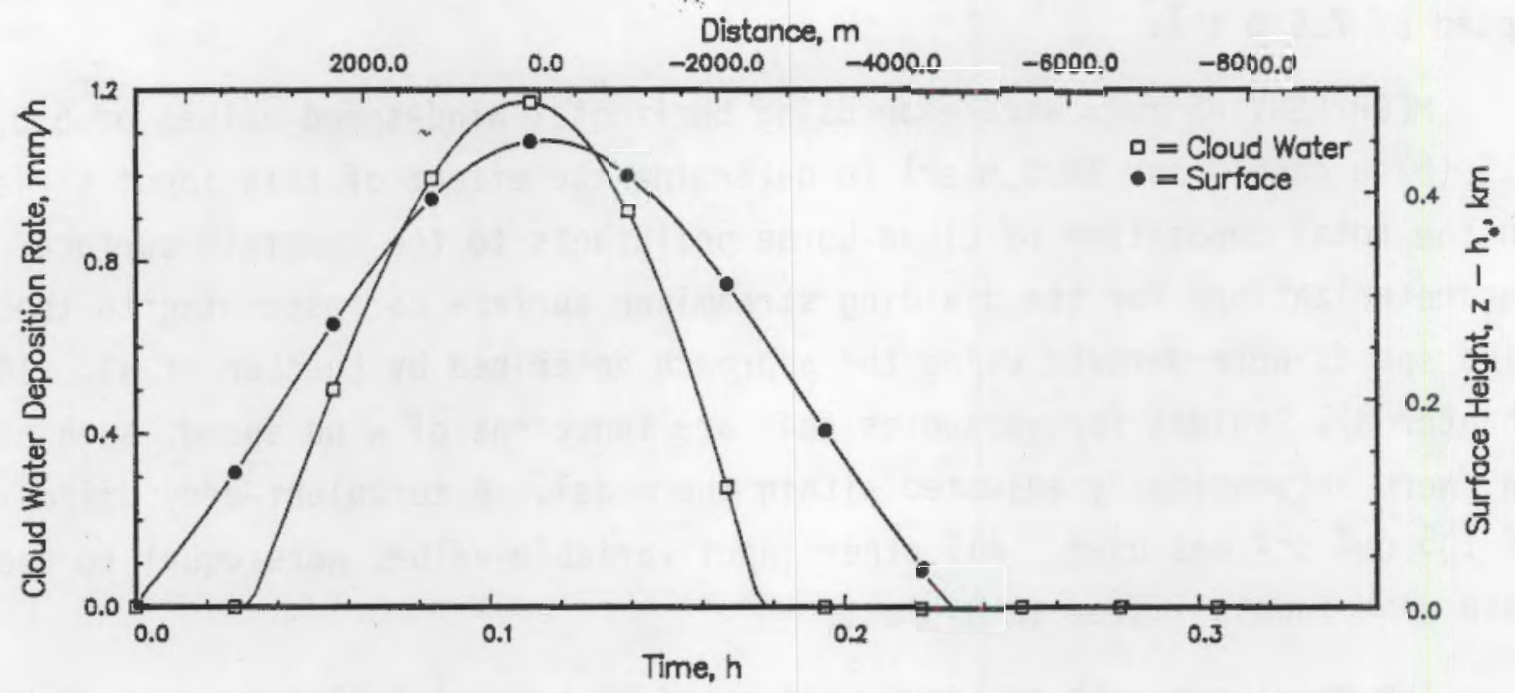

FIGURE 10. Cloud-Water Deposition Rate at a Wind Speed of $10 \mathrm{~m} \mathrm{~s}-1$

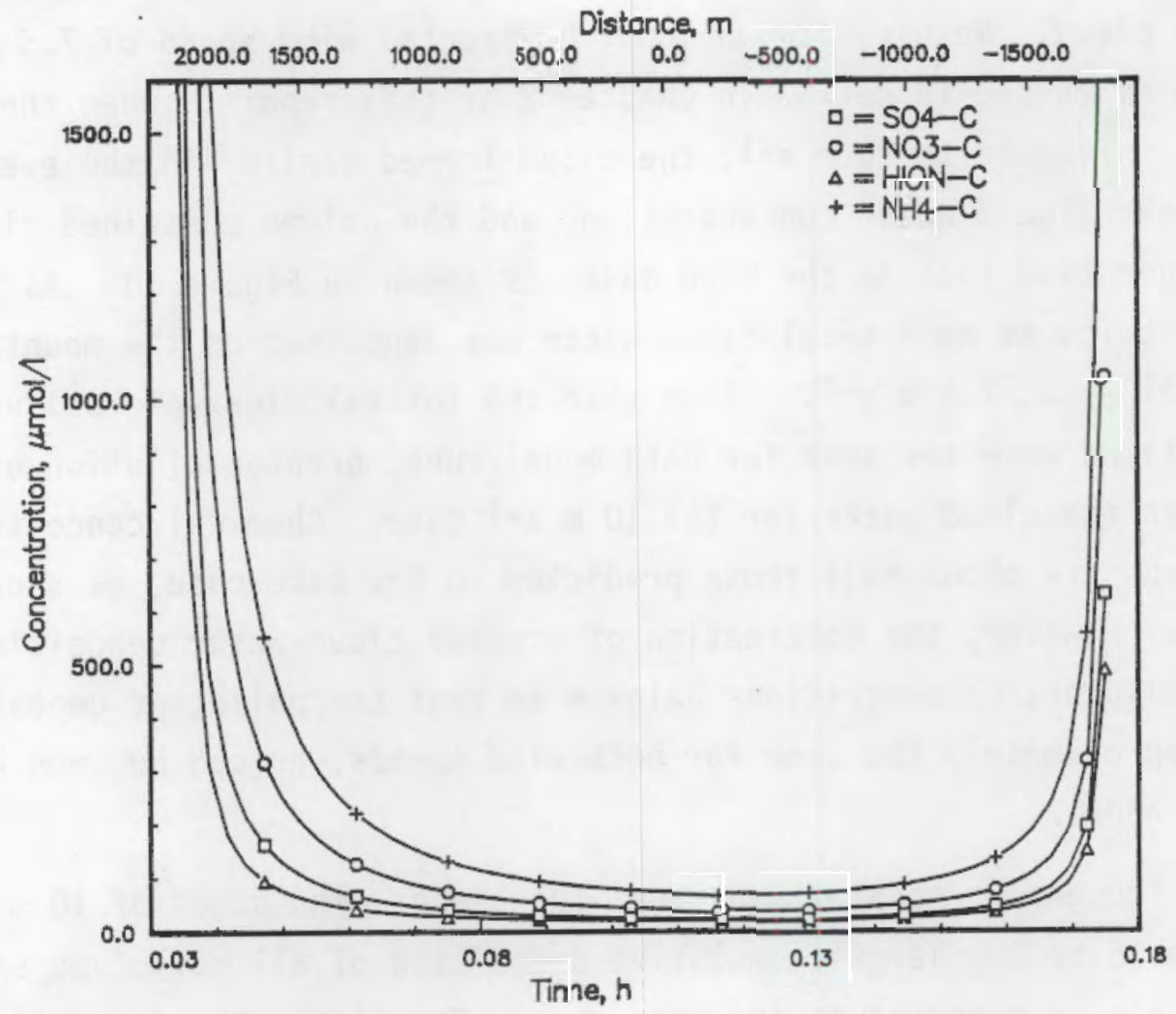

FIGURE 11. $\mathrm{SO}_{4}{ }^{2-}, \mathrm{NO}_{3}^{-}, \mathrm{H}^{+}$, and $\mathrm{NH}_{4}^{+}$Concentrations Within Depositing Cloud Water for a Wind Speed of $10 \mathrm{~m} \mathrm{~s}^{-1}$ 
the $\mathrm{H}^{+}$concentration is lower than in the base case and, as previously discussed, the solubility of $\mathrm{SO}_{2}$ is $\mathrm{pH}$ dependent.

\subsubsection{Wind Shear}

In the base case, we used a constant horizontal wind speed that did not vary with height above the dividing streamline surface. In nature, wind speed is often a function of altitude, a condition known as wind shear. To investigate the effect of wind shear on deposition predicted by MCCP PLUVIUS, we incorporated an altitude-dependent wind speed. For this model run, wind speed was assumed to be $7.5 \mathrm{~m} \mathrm{~s}^{-1}$ at the dividing streamline height and to increase linearly to $10 \mathrm{~m} \mathrm{~s}^{-1}$ at $0.2 \mathrm{~km}$ above this height. Above $0.2 \mathrm{~km}$, the wind speed remained constant at $10 \mathrm{~m} \mathrm{~s}-1$. These conditions produced slightly smaller concentrations of liquid water within the cloud, but higher pollutant concentrations because more air was processed than in the base case. Pollutant deposition fluxes were only slightly larger than in the base case.

\subsection{VARIATION OF CHEMICAL PARAMETERS}

Addressing the questions posed at the beginning of this chapter requires scrutiny of seven main chemical species: sulfate aerosol, ammonium aerosol, gas-phase hydrogen peroxide, gas-phase sulfur dioxide, gas-phase nitric acid, nitrate aerosol, and gas-phase ammonia. Table 9 summarizes the input concentrations of these species used in the various sensitivity runs. All runs were conducted using base case meteorological parameters, i.e., a

horizontal wind speed of $7.5 \mathrm{~m} \mathrm{~s}-1$, a deposition velocity of $56 \mathrm{~cm} \mathrm{~s}^{-1}$, and a turbulent-eddy diffusivity of $10^{5} \mathrm{~cm}^{2} \mathrm{~s}-1$. Input values of other parameters were identical to those in the base case, with initial ground level HCHO at $2 \mathrm{ppb}, 0_{3}$ at $70 \mathrm{ppb}$, temperature at $284.15 \mathrm{~K}$, and pressure at $0.84 \times 106$ dynes $\mathrm{cm}^{-2}$.

\subsection{1 $\underline{\mathrm{H}}_{2} \mathrm{O}_{2} / \mathrm{SO}_{2}$ Ratios}

Ozone and $\mathrm{H}_{2} \mathrm{O}_{2}$ are considered to be the atmospheric oxidants primarily responsible for the aqueous-phase conversion of $\mathrm{SO}_{2}$ to $\mathrm{SO}_{4}{ }^{2-}$ (Penkett et al. 1979; Martin 1984). We focussed our sensitivity studies initially on the $\mathrm{SO}_{2}-\mathrm{H}_{2} \mathrm{O}_{2}$ mechanism, because the rate via this reaction is much greater than that of the $\mathrm{pH}$-dependent $\mathrm{SO}_{2}-\mathrm{O}_{3}$ reaction for the low $\mathrm{pH}$ values typically 

TABLE 9. Summary of Input Conditions for Chemical Parameter
Sensitivity Studies

\begin{tabular}{|c|c|c|c|c|c|c|c|}
\hline & $\begin{array}{l}\text { Aerosol } \\
\mathrm{SO}^{2}{ }^{2-}\end{array}$ & $\begin{array}{l}\text { Aerosol } \\
\mathrm{NH}_{4}^{+}\end{array}$ & $\begin{array}{r}\text { Initi } \\
\text { Gas-Phase } \\
\mathrm{H}_{2} \mathrm{O}_{2} \\
\end{array}$ & $\begin{array}{l}\text { Mixing Ra } \\
\text { Gas-Phase } \\
\text { S02 }\end{array}$ & $\begin{array}{l}\text { tio (ppb) } \\
\text { Gass-Phase } \\
\text { HNO3 }^{2}\end{array}$ & $\begin{array}{l}\text { Aerosol } \\
\mathrm{NO}_{3}^{-}\end{array}$ & $\begin{array}{c}\text { Gas-Phase } \\
\mathrm{NH}_{3} \\
\end{array}$ \\
\hline Base Case & 2. & 5. & 1. & 2. & 3. & 1. & 2. \\
\hline $\mathrm{H}_{2} \mathrm{O}_{2} / \mathrm{SO}_{2}$ Ratios & $\begin{array}{l}0 . \\
0 . \\
0 . \\
0 . \\
0 . \\
0 . \\
0 . \\
0 . \\
0 . \\
0 . \\
0 . \\
0 .\end{array}$ & $\begin{array}{l}0 . \\
0 . \\
0 . \\
0 . \\
0 . \\
0 . \\
0 . \\
0 . \\
0 . \\
0 . \\
0 . \\
0 .\end{array}$ & $\begin{array}{c}0 . \\
0 . \\
.1 \\
.1 \\
.1 \\
1 . \\
1 . \\
1.5 \\
2 . \\
4 . \\
8 . \\
10 .\end{array}$ & $\begin{array}{r}2 . \\
20 . \\
2 . \\
20 . \\
20 . \\
20 \\
20 . \\
2 . \\
2 . \\
20 . \\
20 . \\
20 .\end{array}$ & $\begin{array}{l}0 . \\
0 . \\
0 . \\
0 . \\
0 . \\
0 . \\
0 . \\
0 . \\
0 . \\
0 . \\
0 . \\
0 .\end{array}$ & $\begin{array}{l}0 . \\
0 . \\
0 . \\
0 . \\
0 . \\
0 . \\
0 . \\
0 . \\
0 . \\
0 . \\
0 . \\
0 .\end{array}$ & $\begin{array}{l}0 . \\
0 . \\
0 . \\
0 . \\
0 . \\
0 . \\
0 . \\
0 . \\
0 . \\
0 . \\
0 . \\
0 .\end{array}$ \\
\hline
\end{tabular}

Neutralization

Ratios

$\begin{array}{lll}2 . & 0 . & 1 . \\ 2 . & 2 . & 1 . \\ 2 . & 4 . & 1 . \\ 2 . & 6 . & 1 . \\ 2 . & 8 . & 1 .\end{array}$

Pre-formed

Sulfate Aerosol

$\begin{array}{rrr}0 . & 1 . & 1 . \\ 1 . & 3 . & 1 . \\ 4 . & 9 . & 1 . \\ 10 . & 21 . & 1 . \\ 15 . & 31 . & 1 . \\ 20 . & 41 . & 1 .\end{array}$

Effect of $\mathrm{HNO}_{3}$

$\begin{array}{lll}2 . & 5 . & 1 . \\ 2 . & 5 . & 1 . \\ 2 . & 5 . & 1 . \\ 2 . & 5 . & 1 .\end{array}$

Effect of $\mathrm{NH}_{3}$

$\begin{array}{lll}2 . & 5 . & 1 . \\ 2 . & 5 . & 1 . \\ 2 . & 5 . & 1 . \\ 2 . & 5 . & 1 . \\ 2 . & 5 . & 1 . \\ 2 . & 5 . & 1 .\end{array}$

Effect on Nitrogen Deposition

$\begin{array}{rll}2 . & 5 . & 1 . \\ 2 . & 4 . & 1 . \\ 10 . & 4 . & 1 .\end{array}$

2.
2.
2.
2.
2.

$\begin{array}{ll}4 . & 0 . \\ 4 . & 0 . \\ 4 . & 0 . \\ 2 . & 2 . \\ 0 . & 4 .\end{array}$

0.

0.

0 .

0 .

0 . 


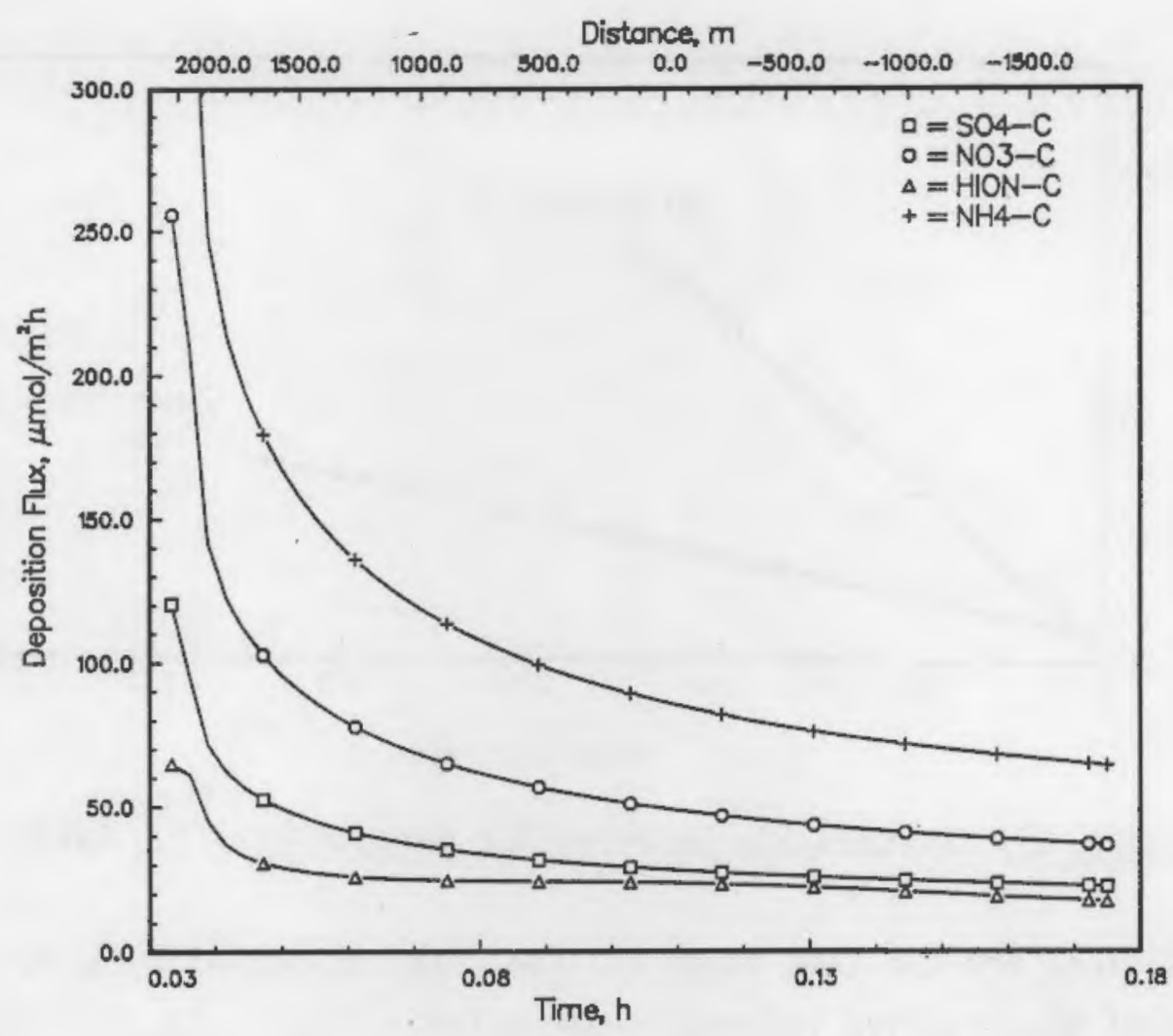

FIGURE 12. Deposition Fluxes for $\mathrm{SO}_{4}^{2-}, \mathrm{NO}_{3}^{-}, \mathrm{H}^{+}$, and $\mathrm{NH}_{4}^{+}$for a Wind Speed of $10 \mathrm{~m} \mathrm{~s}^{-1}$

observed in Mt. Mitchell cloud water samples. By including runs in which the $\mathrm{H}_{2} \mathrm{O}_{2}$ concentration was set to zero, the relative importance of the ozone oxidation reaction under the selected input conditions could be determined and the validity of this approach assessed. Input concentrations of sulfate aerosol, $\mathrm{NH}_{3}$, and $\mathrm{HNO}_{3}$ were set tozero to isolate the effect of the aqueousphase $\mathrm{SO}_{2}$ reactions. For each run, the percentage of $\mathrm{SO}_{2}$ oxidized to $\mathrm{SO}_{4}{ }^{2-}$ was calculated using Equation (12) with column inflow and outflow concentrations determined at 540 and $1110 \mathrm{~s}$, respectively (see Section 2.3).

Figure 13 illustrates the calculated percentage of $\mathrm{SO}_{2}$ oxidized for various inputs of $\mathrm{H}_{2} \mathrm{O}_{2}$ at 2 and $20 \mathrm{ppb} \mathrm{SO_{2 }}$. Runs were limited to conditions where the $\mathrm{H}_{2} \mathrm{O}_{2} / \mathrm{SO}_{2}$ ratio was less than or equal to one, to ensure meeting the equilibrium scavenging assumption inherent in MCCP PLUVIUS. As discussed in Section 2.4, the actual value calculated for the percent oxidation in a given case is influenced by the vertical extent of the air-column grid used within the model and the meteorological conditions being simulated. However, because 


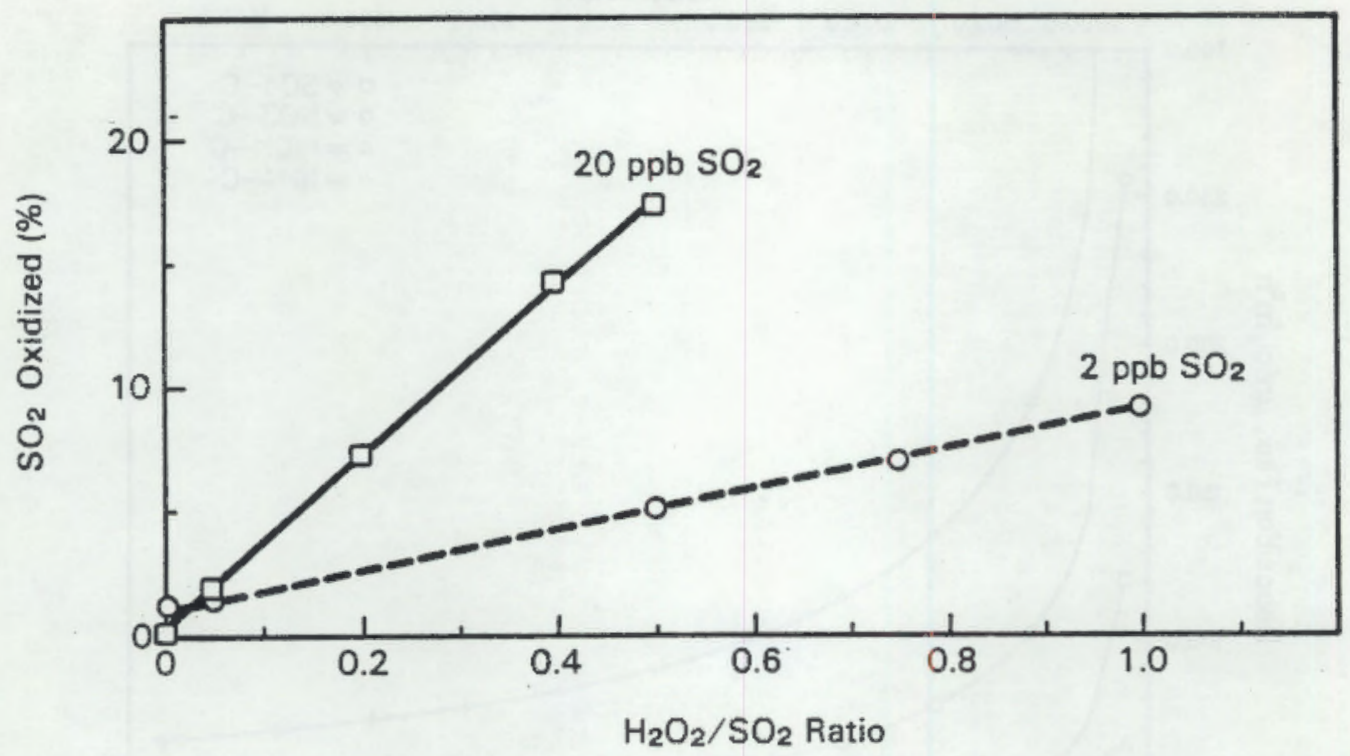

FIGURE 13. Percent $\mathrm{SO}_{2}$ Oxidized for Various $\mathrm{H}_{2} \mathrm{O}_{2} / \mathrm{SO}_{2}$ Ratios

these conditions are the same among all the chemical sensitivity runs, comparison of the relative values, as presented in Figure 13, is instructive in assessing the influence of various pollutants on $\mathrm{SO}_{2}$ oxidation rates. The curves in Figure 13 illustrate that, under the conditions tested, the vast majority of $\mathrm{SO}_{2}$ present in the modeled air parcel at the instant of cloud formation remains in the +4 oxidation state upon cloud evaporation. Even under relatively high pollutant loadings of $10 \mathrm{ppb} \mathrm{H}_{2} \mathrm{O}_{2}$ and $20 \mathrm{ppb} \mathrm{SO} 2$, only about $17 \%$ of the $\mathrm{SO}_{2}$ is converted to sulfate within the air column.

Cumulative deposition curves for sulfate and hydrogen ions for the various $\mathrm{H}_{2} \mathrm{O}_{2} / \mathrm{SO}_{2}$ ratios are shown in Figure 14 . In the $2 \mathrm{ppb} \mathrm{SO}_{2}$ runs, cumulative sulfate deposition to the mountain is substantially less than in the base case, with deposition amounts 7 to 40 times lower depending on the $\mathrm{H}_{2} \mathrm{O}_{2}$ concentration. Cumulative $\mathrm{H}^{+}$deposition was 2 to 6 times lower in these same runs relative to the base case. Together these results suggest that, under typical conditions, in-cloud oxidation of $\mathrm{SO}_{2}$ is not the dominant source of $\mathrm{SO}_{4}{ }^{2-}$ deposited to the surface of Mt. Mitchell. This result is not unexpected given the relatively short lifetime ( $6 \mathrm{~min}$ for the base case run) of the cloud droplets.

The $y$-intercepts of the curves in Figure 13 also illustrate that the $0_{3}$ $\mathrm{SO}_{2}$ reaction produces only a small portion of the cloud water $\mathrm{SO}_{4}{ }^{2-}$ for the 


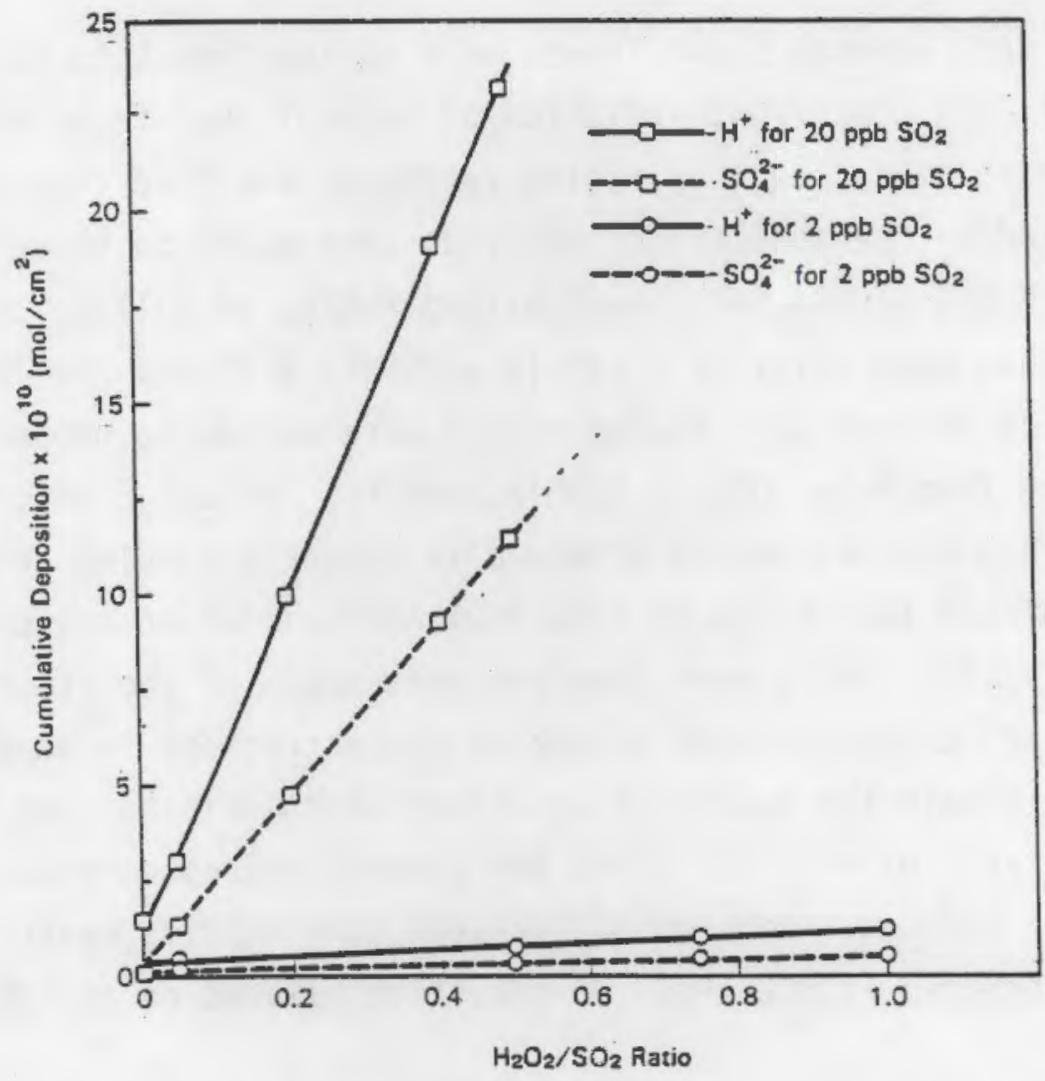

FIGURE 14. Cumulative $\mathrm{SO}_{4} 2-$ and $\mathrm{H}^{+}$Deposition for Various $\mathrm{H}_{2} \mathrm{O}_{2} / \mathrm{SO}_{2}$ Ratios

tested conditions. At $2 \mathrm{ppb} \mathrm{SO} 2$, just $1.1 \%$ of the $\mathrm{SO}_{2}$ is oxidized in the cloud by $70 \mathrm{ppb}$ ozone, and for $20 \mathrm{ppb} \mathrm{S0} 2$, the figure drops to $0.1 \%$. Care must be used in interpreting this finding, because it is known that the $\mathrm{O}_{3}-\mathrm{SO}_{2}$ rate can surpass the $\mathrm{H}_{2} \mathrm{O}_{2}-\mathrm{SO}_{2}$ rate in the presence of neutralizing substances that maintain aqueous-phase $\mathrm{pH}$ above 5 (Martin 1984). However, under the conditions modeled, it appears that the $\mathrm{H}_{2} \mathrm{O}_{2}-\mathrm{SO}_{2}$ reaction is responsible for more aqueous phase $\mathrm{SO}_{4}{ }^{2-}$ production than is the $\mathrm{O}_{3}-\mathrm{H}_{2} \mathrm{O}_{2}$ reaction, but that both aqueous-phase reactions are relatively minor contributors to the total sulfate deposited on the mountain surface.

\subsubsection{Pre-Existing Sulfate Aerosol}

Aerosol measurements can be used not only for identifying major aerosol constituents but also for determining how much acidity is associated with the aerosol. Therefore, two sets of runs focussing on these areas were conducted to investigate the effect of pre-existing sulfate aerosol on sulfate deposition. 
In the first set, aerosol $\mathrm{SO}_{4}{ }^{2-}$ inputs were varied from 0 to $20 \mathrm{ppb}$ ( 0 to 82 $\mu \mathrm{g} \mathrm{SO} 4^{2-} \mathrm{m}^{-3}$ ) with concurrent variation of aerosol $\mathrm{NH}_{4}^{+}$to maintain totally neutralized particles. Initial mixing ratios of the five remaining major species studied in the sensitivity analyses were equal to those used in the base case. In the second set, input mixing ratios of sulfate aerosol were left at the base case level of $2 \mathrm{ppb}\left(8 \mu \mathrm{g} \mathrm{SO} 4^{2-} \mathrm{m}^{-3}\right)$ but the input aerosol $\mathrm{NH}_{4}{ }^{+}, \mathrm{HNO}_{3}$, and aerosol $\mathrm{NO}_{3}^{-}$mixing ratios were varied to produce neutralization ratios varying from 0 to $100 \%$ in $25 \%$ increments. Although neutralization ratios less than $80 \%$ are seldom observed in properly sampled aerosol particles, examination of the full range of 0 to $100 \%$ neutralization ratios within the sensitivity tests allows a more complete assessment of the effect of preexisting aerosol composition on pollutant concentrations in deposited cloud water. To eliminate the neutralizing effect of ammonia gas and better isolate the effect of aerosol acidity, input $\mathrm{NH}_{3}$ concentrations were set to zero in the second set of runs. With no $\mathrm{NH}_{3}$ present, the initial neutralization ratio for species included in MCCP PLUVIUS can be calculated on an equivalent basis as

Initial Neutralization Ratio $=$

$$
\text { Aerosol } \mathrm{NH}_{4}^{+} /\left[\left(2 \times \text { Aerosol } \mathrm{SO}_{4}{ }^{2-}\right)+\left(\mathrm{HNO}_{3}\right)+\left(\text { Aerosol } \mathrm{NO}_{3}{ }^{-}\right)\right]
$$

Both aerosol $\mathrm{NO}_{3}^{-}$and gaseous $\mathrm{HNO}_{3}$ must be considered in this ratio because of the high solubility of $\mathrm{HNO}_{3}$.

Results of the first set of runs are illustrated in Figure 15. The cumulative deposition of $\mathrm{SO}_{4}{ }^{2-}$ is a linear function of the initial sulfate aerosol concentration, supporting the base case analysis, which indicated that only a small percentage of the deposited $\mathrm{SO}_{4} 2-$ was formed within the cloud. Hydrogen ion deposition is not significantly affected, as expected, given that this set of runs simulated the scavenging of totally neutralized ammonium sulfate aerosol. Hydrogen ion deposition does increase very slightly as the aerosol loading is varied from 0 to $20 \mathrm{ppb}$, as a result of the increased aqueous-phase concentration of $\mathrm{NH}_{4}{ }^{+}$, which limits the additional absorption of neutralizing ammonia gas.

Results of the second set of runs are illustrated in Figure 16. Sulfate deposition in these runs remains essentially constant because the aerosol $\mathrm{SO}_{4}{ }^{2-}$ 


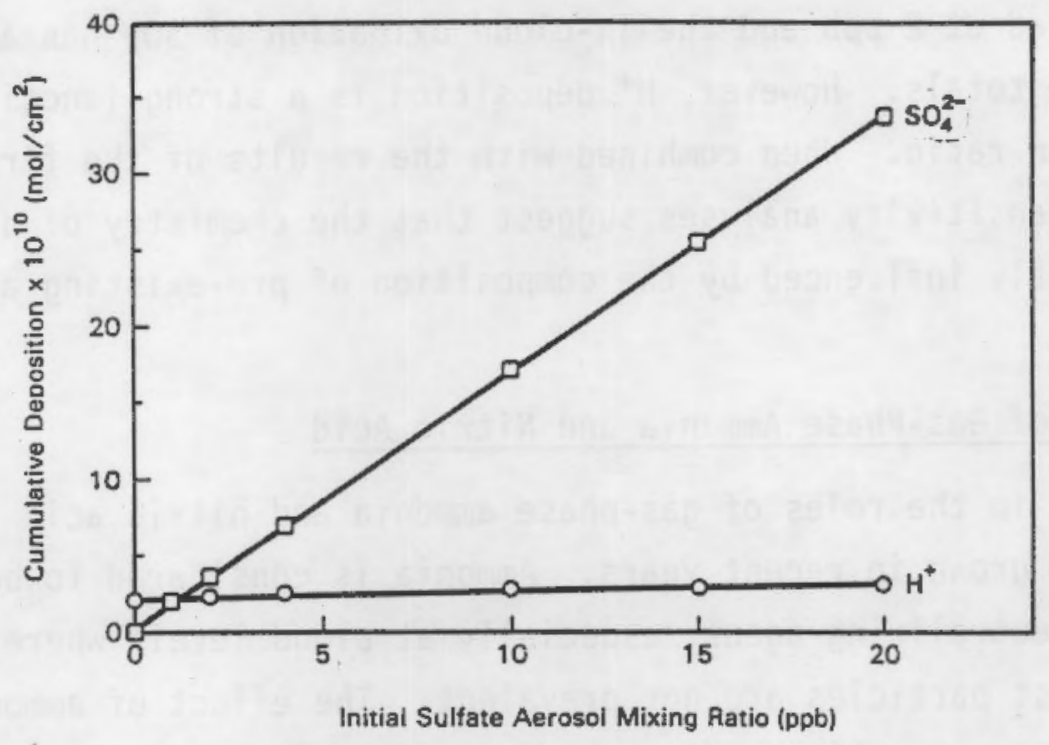

FIGURE 15. Cumulative $\mathrm{SO}_{4}{ }^{2-}$ and $\mathrm{H}^{+}$Deposition as a Function of the Initial Sulfate Aerosol Mixing Ratio (Fully Neutralized Aerosol)

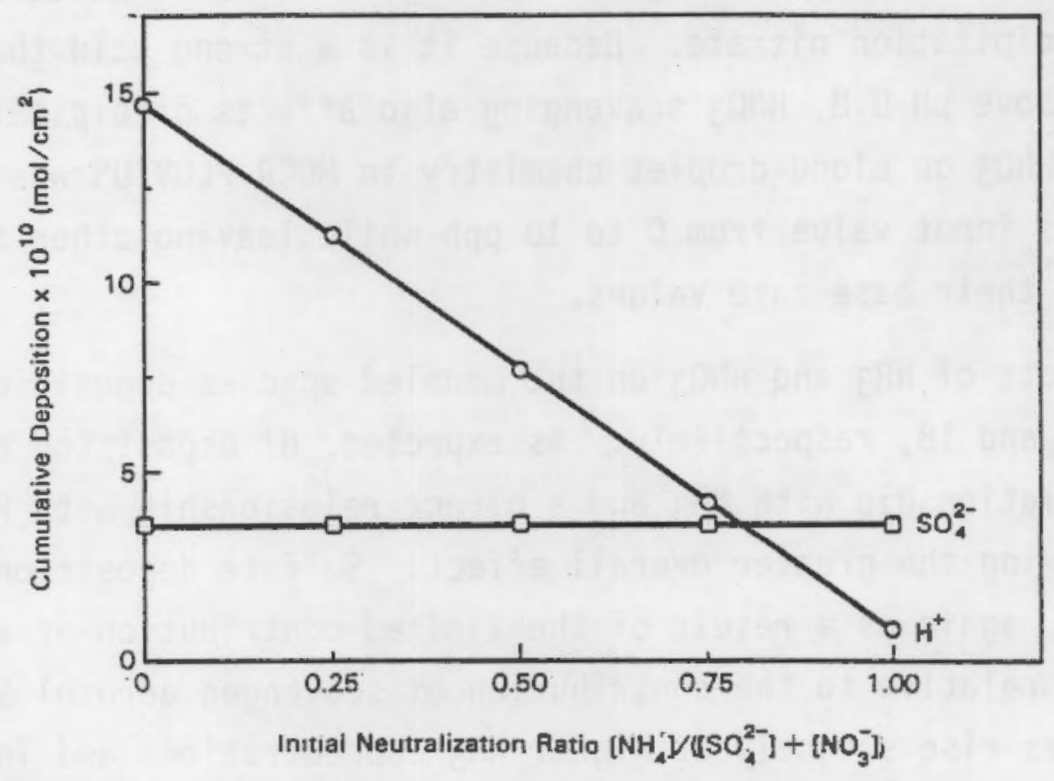

FIGURE 16. Cumulative $\mathrm{S}_{4} 4^{2-}$ and $\mathrm{H}^{+}$Deposition as a Function of the Initial Aerosol Neutralization Ratio 
input was fixed at $2 \mathrm{ppb}$ and the in-cloud oxidation of $\mathrm{SO}_{2}$ has a limited effect on deposition totals. However, $\mathrm{H}^{+}$deposition is a strong function of the neutralization ratio. When combined with the results of the first set of runs, these sensitivity analyses suggest that the chemistry of deposited cloud water is greatly influenced by the composition of pre-existing aerosol particles.

\subsubsection{Effect of Gas-Phase Ammonia and Nitric Acid}

Interest in the roles of gas-phase ammonia and nitric acid in atmospheric chemistry has grown in recent years. Ammonia is considered to be a primary atmospheric neutralizing agent, especially at cloud levels where calciumcontaining dust particles are not prevalent. The effect of ammonia on clouddroplet chemistry in MCCP PLUVIUS was investigated by varying $\mathrm{NH}_{3}$ inputs from 0 to $10 \mathrm{ppb}$ while all other chemical parameters remained at their base case values. Nitric acid is a product of photochemically initiated gas-phase reactions and, because of its high solubility, is considered to be an important source of precipitation nitrate. Because it is a strong acid that fully dissociates above $\mathrm{pH} 0.8, \mathrm{HNO}_{3}$ scavenging also affects precipitation $\mathrm{pH}$. The influence of $\mathrm{HNO}_{3}$ on cloud-droplet chemistry in MCCP PLUVIUS was investigated by varying its input value from 0 to $10 \mathrm{ppb}$ while leaving other chemical parameters at their base case values.

The effects of $\mathrm{NH}_{3}$ and $\mathrm{HNO}_{3}$ on the modeled species deposition are shown in Figures 17 and 18, respectively. As expected, $\mathrm{H}^{+}$deposition demonstrates an inverse relationship with $\mathrm{NH}_{3}$ and a direct relationship with $\mathrm{HNO}_{3}$, with the latter having the greater overall effect. Sulfate deposition totals change only slightly, again as a result of the limited contribution of aqueous-phase $\mathrm{SO}_{2}$ oxidation relative to the contribution of scavenged aerosol $\mathrm{SO}_{4}^{2-}$. Sulfate deposition does rise slightly at higher $\mathrm{NH}_{3}$ concentrations and in the absence of $\mathrm{HNO}_{3}$ due to the increased solubility of $\mathrm{SO}_{2}$ (and therefore the higher overall oxidation rate) at higher pH levels. The effect of various $\mathrm{NH}_{3}$ and $\mathrm{HNO}_{3}$ inputs on the total amount of $\mathrm{SO}_{2}$ oxidized within the cloud is illustrated in Figure 19, plotted using Equation (12). The curves demonstrate the strong effect of $\mathrm{HNO}_{3}$ and $\mathrm{NH}_{3}$ on the $\mathrm{SO}_{2}$ oxidation rate. Note that, using a droplet transit time of $6 \mathrm{~min}$, the results of the $10 \mathrm{ppb} \mathrm{NH} 3$ run convert to an $\mathrm{SO}_{2}$ oxidation rate of over $220 \% / \mathrm{h}$. Under meteorological conditions that produce 


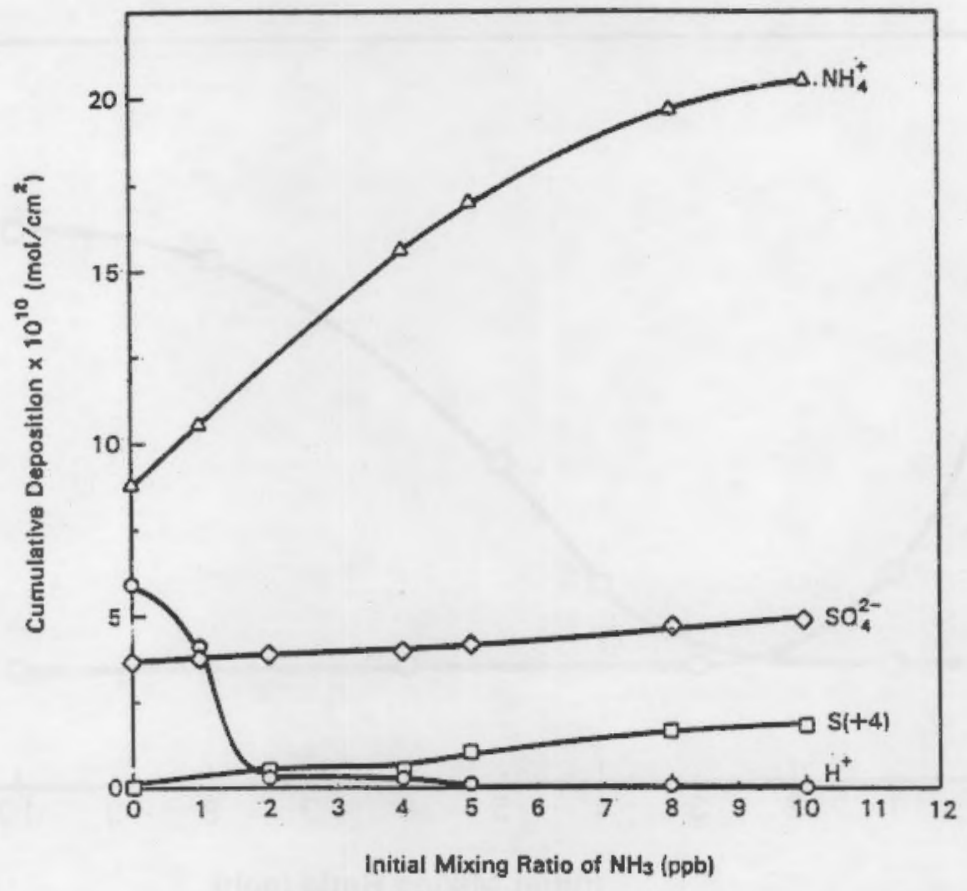

FIGURE 17. Cumulative Deposition of $\mathrm{SO}_{4} 2-, \mathrm{H}^{+}, \mathrm{NH}_{4}{ }^{+}$, and $\mathrm{S}(+4)$ as a Function of the Initial $\mathrm{NH}_{3}$ Mixing Ratio

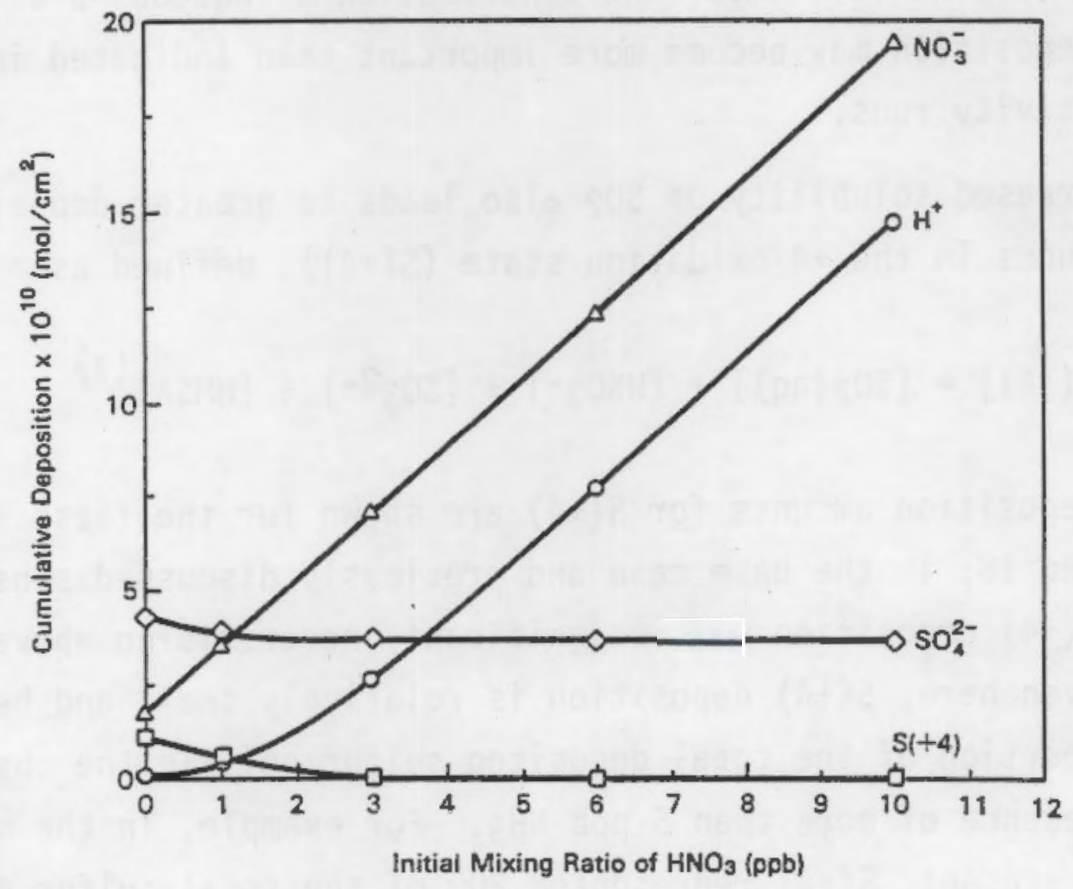

FIGURE 18. Cumulative Deposition of $\mathrm{SO}_{4}{ }^{2-}, \mathrm{H}^{+}, \mathrm{NO}_{3}-$, and $\mathrm{S}(+4)$ as a Function of the Initial $\mathrm{HNO}_{3}$ Mixing Ratio 


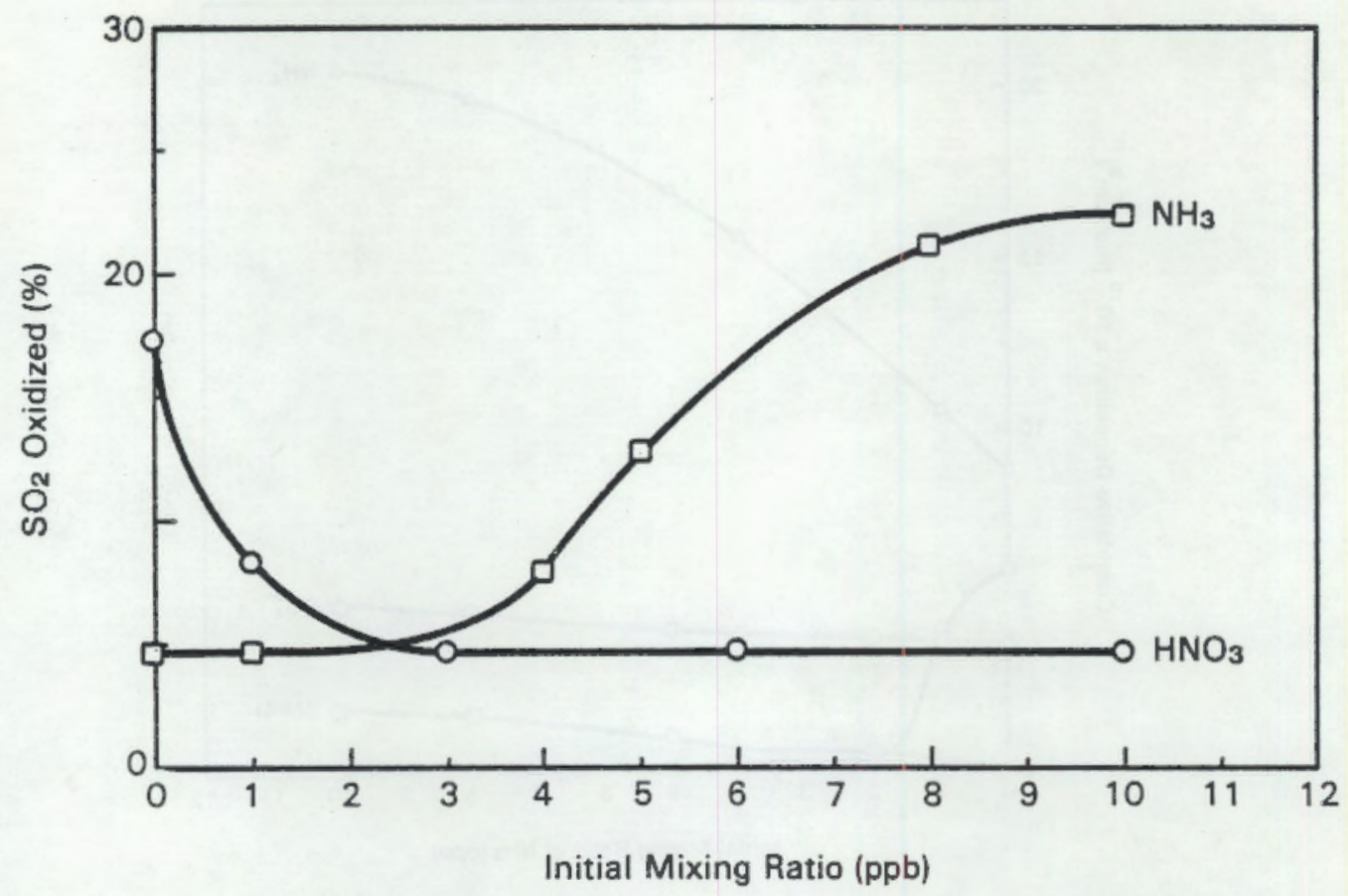

FIGURE 19. Percent $\mathrm{SO}_{2}$ Oxidized as a Function of $\mathrm{NH}_{3}$ and $\mathrm{HNO}_{3}$ Mixing Ratios

longer cloud-droplet lifetimes, the contribution of aqueous-phase $\mathrm{SO}_{2}$ oxidation to sulfate deposition may become more important than indicated in the current set of sensitivity runs.

The increased solubility of $\mathrm{SO}_{2}$ also leads to greater deposition of aqueous sulfur compounds in the +4 oxidation state $(S(+4))$, defined as

$$
[\mathrm{S}(+4)]=\left[\mathrm{SO}_{2}(\mathrm{aq})\right]+\left[\mathrm{HSO}_{3}-\right]+\left[\mathrm{SO}_{3}{ }^{2-}\right]+\left[\mathrm{HMSA}^{(\mathrm{a})}\right.
$$

Cumulative deposition amounts for $S(+4)$ are shown for the first time in Figures 17 and 18; in the base case and previously discussed sensitivity runs, cumulative $S(+4)$ deposition was insignificant, never rising above $0.02 \times 10-10$ mol $\mathrm{cm}^{-2}$. Even here, $S(+4)$ deposition is relatively small and becomes a significant portion of the total deposited sulfur only in the absence of $\mathrm{HNO}_{3}$ or in the presence of more than $5 \mathrm{ppb} \mathrm{NH}_{3}$. For example, in the modeling run with no $\mathrm{HNO}_{3}$ present, $\mathrm{S}(+4)$ represented $20 \%$ of the total sulfur deposition,

(a) Note that the definition for $S(+4)$ differs from that of $S(I V)$ given in Equation (7) by the inclusion of HMSA. 
and in the run with $10 \mathrm{ppb} \mathrm{NH} 3$, this figure rose to $25 \%$. In all runs where cumulative $S(+4)$ deposition was above $10-11 \mathrm{~mol} \mathrm{~cm}^{-2}$, HMSA represented at least $25 \%$ of the deposited $S(+4)$. In low acidity situations (0 ppb $\mathrm{HNO}_{3}$ or $10 \mathrm{ppb} \mathrm{NH}_{3}$ ), the contribution of HMSA exceeded that of dissolved $\mathrm{SO}_{2}$.

The results of these runs indicate that $\mathrm{HNO}_{3}$ and $\mathrm{NH}_{3}$ have a strong influence on aqueous-phase chemistry, from both a solubility standpoint and a reaction-rate standpoint, and on pollutant-deposition loadings to the surface.

\subsubsection{Gas/Aerosol Partitioning of Nitrogen Compounds}

Sensitivity runs were also conducted to examine factors influencing the deposition of nitrogen species to the mountain surface. Varying input gas to aerosol ratios did not affect the cumulative deposition or the cloud-water concentrations of ammonium and nitrate ions, if the total input sums of aerosol $\mathrm{NH}_{4}{ }^{+}$plus $\mathrm{NH}_{3}$ and aerosol $\mathrm{NO}_{3}$ - plus $\mathrm{HNO}_{3}$ remain constant. This is a result of the high solubility of both the aerosol and gaseous forms of these species; when a cloud exists, all of the aerosol and essentially all of the gas is incorporated into the cloud water.

Since $\mathrm{HNO}_{3}$ and $\mathrm{NH}_{3}$ solubilities are slightly dependent on the $\mathrm{pH}$, model runs were also made to test the effect of acidity on nitrogen-compound scavenging. The resulting deposition of $\mathrm{NO}_{3}^{-}$and $\mathrm{NH}_{4}{ }^{+}$was not affected when the $\mathrm{pH}$ was varied over a reasonable range for cloud water. Thus, the deposition of nitrogen species modeled by MCCP PLUVIUS is governed mainly by the clearair concentrations of $\mathrm{HNO}_{3}$, aerosol $\mathrm{NO}_{3}-, \mathrm{NH}_{3}$, and aerosol $\mathrm{NH}_{4}^{+}$used as inputs to the model. 


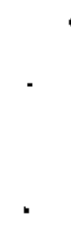




\subsection{DISCUSSION AND IMPLICATIONS OF CURRENT MODELING INVESTIGATION}

The research approach for the current investigation involved running the MCCP PLUVIUS model for typical summertime conditions on Mt. Mitchell, North Carolina, in a base case scenario to study the pollutant scavenging, transformation, and deposition processes occurring in an orographic cloud. Values of selected input parameters were then varied in a sensitivity study to determine the dependence of model results on these parameters. An orographic cloud of realistic dimensions was formed in the model using meteorological data collected during a cloud event at the Mt. Mitchell site. The meteorological data came from a rawinsonde sounding at Greensboro, North Carolina, over $200 \mathrm{~km}$ distant from the mountain. Although not directly investigated in this study, basic thermodynamical and meteorological theory lead us to expect that wind speeds and input humidity profiles will have a profound effect on model results, because cloud formation itself is quite sensitive to these parameters. This emphasizes the need to observe vertical profiles of meteorological variables immediately upwind of the orographic cloud. Interpolation in time and space from the regional network of twicedaily rawinsondes will, in many instances, be insufficiently accurate for model initialization.

Analysis of the base case and sensitivity test results can be combined into an internally consistent set of findings for the chemical and meteorological conditions studied. These findings must be deemed preliminary until a detailed analysis of model predictions versus actual observations is conducted to evaluate the model's operation more fully. The major preliminary findings can be summarized as follows:

- Pollutant aqueous concentrations and deposition fluxes are location dependent. Concentrations are greatest at the edges of the cloud, because of the low liquid water content, and the greatest deposition flux occurs on the windward side of the mountain.

- In-cloud chemical reactions are limited by the time it takes for the air parcels to be carried over the mountain and to form the cloud. For a given humidity profile, bigger clouds are generally formed when wind speeds are large, and smaller clouds are formed when wind speeds are low. The 
transport time, calculated as the pathlength through the cloud divided by the wind speed, may be relatively insensitive to wind speed, because changes in the wind speed also affect the air-parcel pathlength.

- Because of this transport-time limitation, in-cloud oxidation of $\mathrm{SO}_{2}$ makes a limited contribution to total sulfate deposition for typical concentrations of $\mathrm{SO}_{2}, \mathrm{O}_{3}, \mathrm{H}_{2} \mathrm{O}_{2}$, and aerosol $\mathrm{SO}_{4}{ }^{2-}$. Thus, sulfate deposition predicted by MCCP PLUVIUS is effectively determined by the amount of aerosol sulfate existing in the modeled air mass before cloud formation.

- Hydrogen ion deposition predicted by the model is governed by input values for nitric acid and ammonia gas and, by extension, the effective aerosol neutralization ratio.

- Little deposition of sulfur in the +4 oxidation state $(S(+4))$ occurs except at high ammonia concentrations or in the absence of nitric acid. Under these conditions, higher cloud-droplet $\mathrm{pH}$ values lead to enhanced $\mathrm{SO}_{2}$ solubility. However, $\mathrm{S}(+4)$ species still represent a small fraction (less than 25\% in all model runs) of the total sulfur deposition. HMSA formation is also negligible except under similar high $\mathrm{NH}_{3} / \mathrm{low} \mathrm{HNO}_{3}$ conditions, although HMSA can represent a substantial fraction of the $S(+4)$ deposition.

- Under typical conditions, the partitioning between gas-phase $\mathrm{HNO}_{3}$ and aerosol $\mathrm{NO}_{3}$ - has little effect on the total deposition of nitrate to the mountain surface as a result of the high solubility of both species. For the same reason, partitioning between gas-phase $\mathrm{NH}_{3}$ and aerosol $\mathrm{NH}_{4}{ }^{+}$ has little effect on total ammonium deposition.

- Within the model, deposition velocity is calculated as a linear function of wind speed. For base case conditions, total pollutant deposition on the mountain's surface appears to be relatively insensitive to the exact linear relationship employed. The reason for this lies in the depletion of pollutant in the lowest level of the cloud as cloud droplets are deposited. The turbulent-eddy diffusivity, which governs pollutant transfer within the modeled air column, also does not strongly influence total pollutant deposition because of the effect of this parameter on 
cloud characteristics; values that increase pollutant transfer simultaneously decrease the size of the cap cloud. Although the value of $105 \mathrm{~cm}^{2} \mathrm{~s}^{-1}$ recommended for the eddy diffusivity for use in the model is an accepted mid-range value, additional information regarding eddy diffusivities in cap cloud events would be useful in fine-tuning MCCP PLUVIUS.

The findings of this investigation can be compared with those of $\mathrm{Hi11}$, Choularton, and Penkett (1986), who modeled $\mathrm{SO}_{4}^{2-}$ production and deposition to a hill surface from a turbulent cap cloud in the Great Dun Fell region of Great Britain. The cloud-water and pollutant concentration patterns there showed trends similar to the ones presented here: pollutant concentrations were highest at the edges of the cloud, where the liquid water concentration was the lowest. However, in contrast to this study, Hill, Choularton, and Penkett (1986) found that maximum deposition occurred on the lee side of the hill. This difference is a consequence of the very different flow fields used in the two simulations. In both models, deposition is a strong function of wind speed but in the British simulations very high wind speeds developed in the lee of the mountain because of the development of supercritical flow associated with a strong and deep capping inversion over the mountain. Data from Mt. Mitchell are inadequate to verify whether supercritical flow is a common feature of the meteorology. The development of a more complicated flow model is currently not recommended, in view of the data requirements of such a model. Nevertheless, the important differences between model results suggest that additional data should be collected at Mt. Mitchell and that the flow field should receive further study.

Hi11. Choularton, and Penkett (1986) also concluded that in-cloud aqueous oxidation of $\mathrm{SO}_{2}$ can be a significant source of deposited $\mathrm{SO}_{4}{ }^{2-}$ at Great Dun Fell. However, they assumed that concentrations of pre-existing sulfate aerosol at the site were similar to those found in clean maritime air and assigned an input value of approximately $0.4 \mathrm{ppb}(1.6 \mu \mathrm{g} \mathrm{m}-3)$ for aerosol $\mathrm{SO}_{4}^{2-}$, substantially less than the $2 \mathrm{ppb}(8.2 \mu \mathrm{gm}-3)$ aerosol $\mathrm{SO}_{4}{ }^{2-}$ considered representative of Mt. Mitchell. The differences in the findings of the two studies illustrate the importance of knowing, before applying the model, the 
meteorological and chemical characteristics of the air mass to be modeled and the effects of terrain on these characteristics.

When the results of the current modeling study are extended to the actual mountain at Mt. Mitchell, the following general observations can be made:

- Concentration patterns and deposition amounts measured at one site on Mt. Mitchell cannot be arbitrarily extended to the mountain as a whole. Multiple sampling stations, especially on the windward side of the mountain, are desirable.

- To adequately understand the source of sulfate in cloud, it is important to determine the concentration and composition of clear-air aerosols that can act as cloud condensation nuclei. Ideally, these aerosol measurements should be made upwind of Mt. Mitche11, at elevations that sample the actual air mass that will be lifted to form the cap cloud on Mt. Mitchell.

- To adequately understand hydrogen ion deposition, it is important to monitor clear-air concentrations of $\mathrm{HNO}_{3}$ and $\mathrm{NH}_{3}$. Although interstitial air measurements would also be useful, modeling results suggest that, under typical summertime conditions, these gases are almost totally solubilized within the cloud. Nitric acid and $\mathrm{NH}_{3}$ measurements should also provide insight into sources of nitrogen deposited by the cloud.

- Meteorological soundirgs (vertical profiles of wind, temperature, and humidity) must be made in the inmediate vicinity of Mt. Mitchell to properly initialize the model for simulation of actual cap cloud events.

These observations should prove useful in refining the field measurement program at Mt. Mitchell. Application of the MCCP PLUVIUS model should prove useful in developing understanding of the important physicochemical processes occurring within specific cap cloud events on the mountain. However, the results of the current study should not be arbitrarily extended to all MCCP field stations (or any location). A close examination of the topographical, meteorological, and chemical characteristics of each site and event to which the model is to be applied is necessary to tailor MCCP PLUVIUS to a specific application. 
Several suggestions for the further development of MCCP PLUVIUS have been made by Luecken et al. (1987). These included development of the model to include a better parameterization of the roles of cloud microphysics, including the incorporation of droplet-size distributions, entrainment, and turbulent diffusivity. The effect of radiative cooling at cloud top should also be investigated, because it is expected to affect the cloud microphysics. Cloud-water deposition rates are currently parameterized in the model using a simple scheme that could be improved by making the deposition rate an explicit function of the characteristics of the forest or vegetative canopy. Model enhancements of these types, along with the production of site-specific versions of MCCP PLUVIUS, should also prove useful to the MCCP program. 


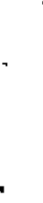




\subsection{REFERENCES}

Easter, R. C., and J. M. Hales. 1984. PLUVIUS: A Generalized One-Dimensional Model of Reactive Pollutant Behavior, Including Dry Deposition, Precipitation Formation, and Wet Removal. 2nd ed. PNL-4046, Pacific Northwest Laboratory, Richland, Washington.

Hales, J. M., and S. L. Sutter. 1973. "Solubility of Sulfur Dioxide in Water at Low Concentrations." Atmos. Environ. 7:997-1001.

Heikes, B. G., G. L. Kok, J. G. Walega and A. L. Lazrus. 1987. " $\mathrm{H}_{2} \mathrm{O}_{2}, \mathrm{O}_{3}$ and $\mathrm{SO}_{2}$ Measurements in the Lower Troposphere Over the Eastern United States During Fall." J. Geophy. Res. 92:915-931.

Hill, T. A., T. W. Choularton and S. A. Penkett. 1986. "A Model of Sulphate Production in a Cap Cloud and Subsequent Turbulent Deposition onto the Hill Surface." Atmos. Environ. 20:1763-1771.

Kelly, T. J., D. H. Stedman and G. L. Kok. 1979. "Measurements of $\mathrm{H}_{2} \mathrm{O}_{2}$ and $\mathrm{HNO}_{3}$ in Rurat Air." Geophys. Res. Let. 6:375-378.

Lovett, G. M., and W. A. Reiners. 1982. "Cloud Water: An Important vector of Atmospheric Deposition." In Precipitation Scavenging, Dry Deposition, and Resuspension, eds. Pruppacher et al., pp. 171-180. Elsevier Science Publishing Co., Inc., New York.

Luecken, D. J., C. D. Whiteman, E. G. Chapman, G. L. Andrews and D. C. Bader. 1987. Description of the Mountain Cloud Chemistry Program (MCCP) Version of the PLUVIUS MOD 5.0 Reactive Storm Simulation Model. PNL-6242, Pacific Northwest Laboratory, Richland, Washington.

Martin, L. R. 1984. "Kinetic Studies of Sulfite Oxidation in Aqueous Solution." In $\underline{\mathrm{SO}}_{2}, \mathrm{NO}$ and $\mathrm{NO}_{2}$ Oxidation Mechanisms: Atmospheric Considerations, ed. J. G. Calvert. Butterworth Publishers, Boston, Massachusetts.

Penkett, S. A., B. M. R. Jones, K. A. Brice and A. E. J. Eggleton. 1979. "The Importance of Atmospheric 0zone and Hydrogen Peroxide in Oxidizing Sulfur Dioxide in Cloud and Rainwater." Atmos. Environ. 13:123-137. 
Seigneur, C., and P. Saxena, 1984. "A Study of Atmospheric Acid Formation in Different Environments." Atmos. Environ. 18:2109-2124.

Spicer, C. W. 1982. "The Distribution of Oxidized Nitrogen in Urban Air." Sci. Total Environ. 24:183-192. 
PNL-6292

UC-11

\section{DISTRIBUTION}

No. of

Copies

OFFSITE

30 DOE Technical Information Center

10 R. L. Bradow

U.S. Environmental Protection Agency ASRL/MD-59

Research Triangle Park, NC 27711

J. L. Durham

ASRL/USEPA MD-59

Research Triangle Park, NC 27711

R. J. Paur

EPA/Mail Drop 44

Environmental Monitoring System Lab

Research Triangle Park, NC 27711

D. Holden

Program Coordination Office

National Acid Precipitation

Assessment Program

722 Jackson Place, N.W.

Washington, DC 20506

E. B. Cowling

Associate Dean, Forest Resources

North Carolina State University

Raleigh, NC 27695-8001

M. Goltz

Department of Plant and Soil

Science

Deering Hall

University of Maine

Orono, ME 04469
No. of

Copies

OFFSITE

J. Hornig

Environmenta] Studies Program

Dartmouth College

Hanover, NH 03755

5 V. Mohnen

Atmospheric Sciences Research Center

SUNY-ES-324

1400 Washington Ave.

Albany, NY 12222

2 S. Mueller

Tennessee Valley Authority

205 CEB

Muscle Shoals, AL 35660

2 V. K. Saxena

Department of Marine, Earth and Atmospheric Sciences

North Carolina State University

Raleigh, NC 27695-8208

2 J. Sigmon

Department of Environmental Sciences

University of Virginia

Charlottesvitle, VA 22906

ONSITE

2 DOE Richland Operations Office

J. J. Sutey

R. A. Rochette 
No. of

Copies

\section{ONSITE}

\section{Pacific Northwest Laboratory}

G. L. Andrews

D. C. Bader

E. G. Chapman

D. W. Dragnich

R. C. Easter

C. E. Elderkin

M. J. Graham

L. K. Grove

J. M. Hales

$P$. C. Hays

R. R. LaBarge

N. S. Laulainen (20)

D. J. Luecken

W. T. Pennel1

J. A. Stottlemyre

C. D. Whiteman (10)

R. E. Wildung

Publishing Coordination (2)

Technical Report Files (5) 
